2014

\title{
FAULT MORPHOLOGY WITHIN THE SOUTHERN KENYAN PORTION OF THE EAST AFRICAN RIFT VALLEY
}

Justin B. Wargelin

Michigan Technological University

Follow this and additional works at: https://digitalcommons.mtu.edu/etds

Part of the Geology Commons

Copyright 2014 Justin B. Wargelin

\section{Recommended Citation}

Wargelin, Justin B., "FAULT MORPHOLOGY WITHIN THE SOUTHERN KENYAN PORTION OF THE EAST

AFRICAN RIFT VALLEY", Master's report, Michigan Technological University, 2014.

https://doi.org/10.37099/mtu.dc.etds/821

Follow this and additional works at: https://digitalcommons.mtu.edu/etds

Cart of the Geology Commons 
FAULT MORPHOLOGY WITHIN

THE SOUTHERN KENYAN PORTION OF THE EAST AFRICAN RIFT

VALLEY

By

Justin B. Wargelin

\begin{abstract}
A REPORT
Submitted in partial fulfillment of the requirements for the degree of

MASTER OF SCIENCE

In Geology
\end{abstract}

MICHIGAN TECHNOLOGICAL UNIVERSITY

2014

(c) 2014 Justin B. Wargelin 
This report has been approved in partial fulfillment of the requirements for the Degree of MASTER OF SCIENCE in Geology.

Department of Geological/Mining Engineering and Sciences

Report Advisor: James R. Wood

Committee Member: Carol A. MacLennan

Committee Member: Alexandria L. Guth

Department Chair: John Gierke 


\section{Dedication:}

To Professor William Gregg who was my Co-Advisor before his death and who motivated me as to questions about geology; and to Professor Jim Wood for introducing me to the East Africa Rift and for persevering with me through the completion of the report. 


\section{Table of Contents}

Introduction: Goals and Hypotheses $\ldots \ldots \ldots \ldots \ldots$

Geologic Setting and Background . . . . . . . . . . . . 13

Method Development . . . . . . . . . . . . . . . 16

Results and Discussion: Data and Observations . . . . . . 21

Limitation of Research and Future Work . . . . . . . . . . . 34

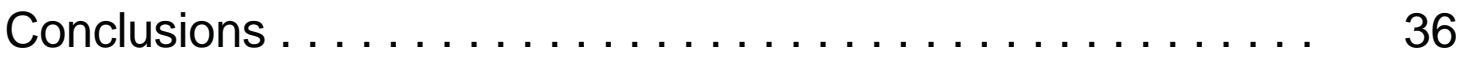

Bibliography . . . . . . . . . . . . . . . 38

Appendices . . . . . . . . . . . . . . . . . . . 40 


\section{List of Figures}

Figure 1: $\quad$ Southern Kenyan Rift 8

Figure 2: Map Showing Outline of Africa and the Middle East 9

Figure 3: $\quad$ Map Showing the Traces of Faults Mapped for This Study 10

Figure 4a: Southern Kenyan Rift Valley 12

Figure 4b: Southern Rift Valley near Nairobi 13

Figure 5: $\quad$ Method 1: Example of Breaking Fault Scarps Profiles into 18 Segments - Fault 1a Profile

Figure 6: $\quad$ Method 1: Fault 1a Segment 1 Profile with Excel Linear 19 Trendline

Figure 7: Theoretical Model of Scarp Erosion--Fault 1a Profile 22

Figure 8: Fault 3J: Corrected for VE 24

Figure 9: Fault 5i as Drawn by Excel: Original VE 25

Figure 10: Fault 5i as Drawn by Excel: Corrected for VE 26

Figure 11: Fault 2n as Drawn by Excel: Original VE 27

Figure 12: Fault 2n as Drawn by Excel: Corrected for VE 27

Figure 13: Buckley et al. Explanation of Development of Loriu 28 Escarpment

Figure 14: Fault 6a as Drawn by Excel: Original VE 30

Figure 15: Fault 6a as Drawn by Excel: Corrected for VE 30

Figure 16: Fault 6a Possible Interpretation 31

Figure 17: Fault 6e as Drawn by Excel: Original VE 32

Figure 18: Fault 6e as Drawn by Excel: Corrected for VE 33

Figure 19: Fault 6e Possible Interpretation 34

Figure 20: Theoretical Model of Scarp Erosion--Fault 1a Profile: 40 VE Example

Figure 21: Fault 1a corrected for VE 


\section{Acknowledgements}

This research project came about because of my brief visit to the area in May of 2008 when I participated in an East African Field Geology course/trip with Dr. James Wood of the Michigan Technological University Geology Department. For the first two weeks of the trip, we stayed in Nairobi, exploring the Rift Valley and the area around Lake Magadi. During the third week we went on "safari" traveling up the Rift Valley to see several of the lakes above Lake Magadi and staying along the lakes themselves. This included Lakes Naivasha, Baringo, Bogoria and Elementaita in that order, seeing Elementaita on the way back to Nairobi. We explored the escarpments and visible fault scarps around this Lake Magadi region. I became interested in how these fault scarps could be studied from afar-as well as on the ground.

I also wish to credit Alexandria Guth for providing me with a valuable tip for tracing faults in the same direction with respect to dip direction, as my shapefiles in Global Mapping were created. 


\section{Abstract}

Faults form quickly, geologically speaking, with sharp, crisp step-like profiles. Logic dictates that erosion wears away this "sharpness" or angularity creating more rounded features. As erosion occurs, debris accumulates at the base of the scarp slope. The stable end point of this process is when the scarp slope approaches an ideal sigmoid shape.

This theory of fault end process, in combination with a new method developed in this report for fault profile delineation, has the potential to enable observation and categorization of fault profiles over large, diverse swaths of fault formation-- in remote areas such as the Southern Kenyan Rift Valley. This up-to date method uses remote sensing data and the digitizer tool in Global Mapper to create shape files of fault segments.

This method can provide further evidence to support the notion that sigmoidalshaped profiles represent a natural endpoint of the erosional process of fault scarps. Over time, faults of many different ages would exist in this similar shape over a wide region. However, keeping in mind that other processes can be at work on scarps-most notably drainage patterns, when anomalies in profiles are observed, reactivation in some form possibly has occurred. 


\section{Introduction: Goals and Hypotheses}

The purpose of this study is to develop a method for examining the geomorphology of the fault-bounded horst blocks in the Southern Kenyan Rift (Fig. 1). In this and other more remote and inaccessible areas, applied remote sensing techniques can prove invaluable when, as often is the case, the resources are lacking to fund more traditional methods of surveying large areas.

Figure 1: Southern Kenyan Rift

Source: Courtesy of Alexandria Guth

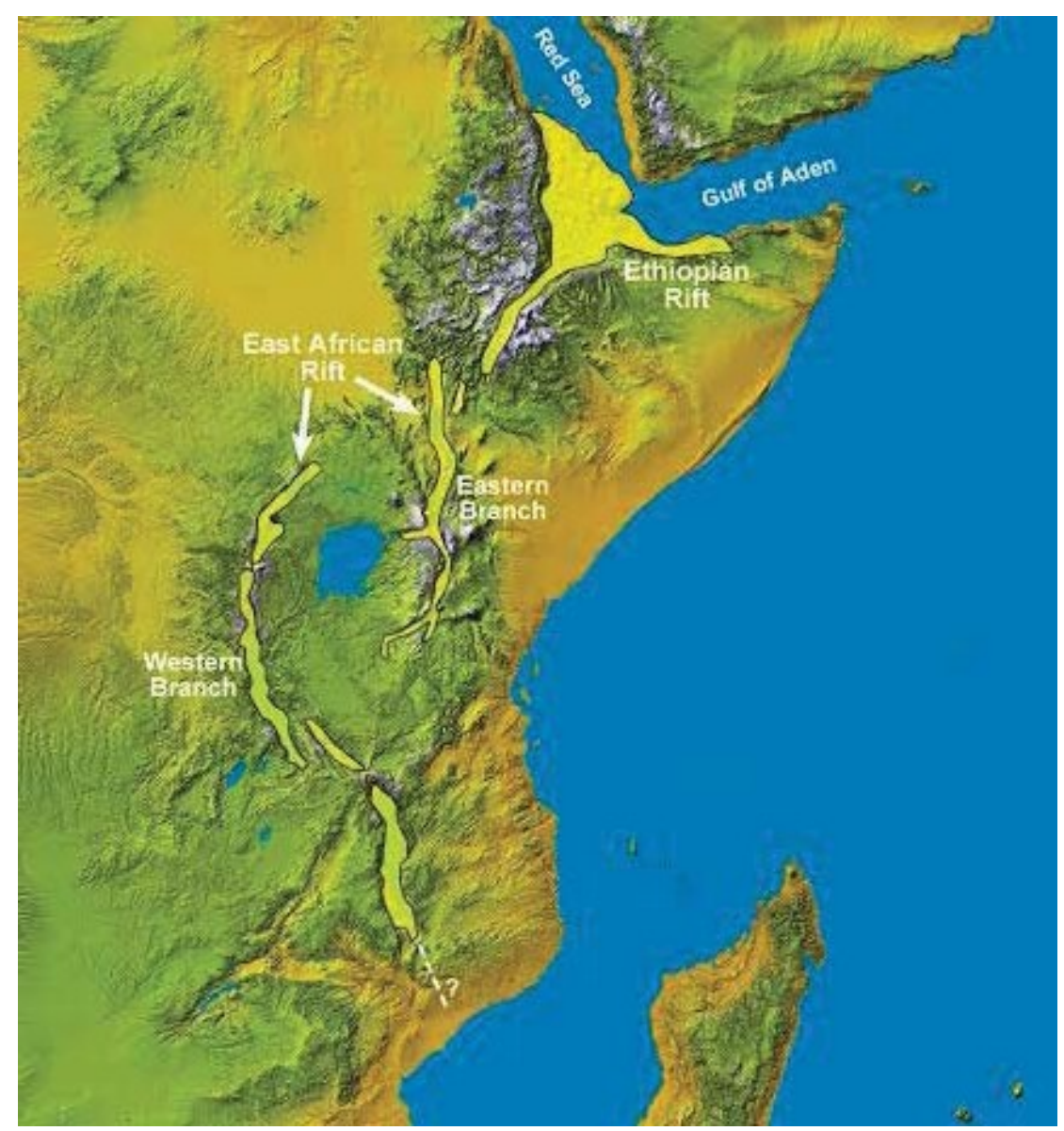


Figure 2: Map Showing Outline of Africa and the Middle East

Box indicates area of study shown in map on following page.

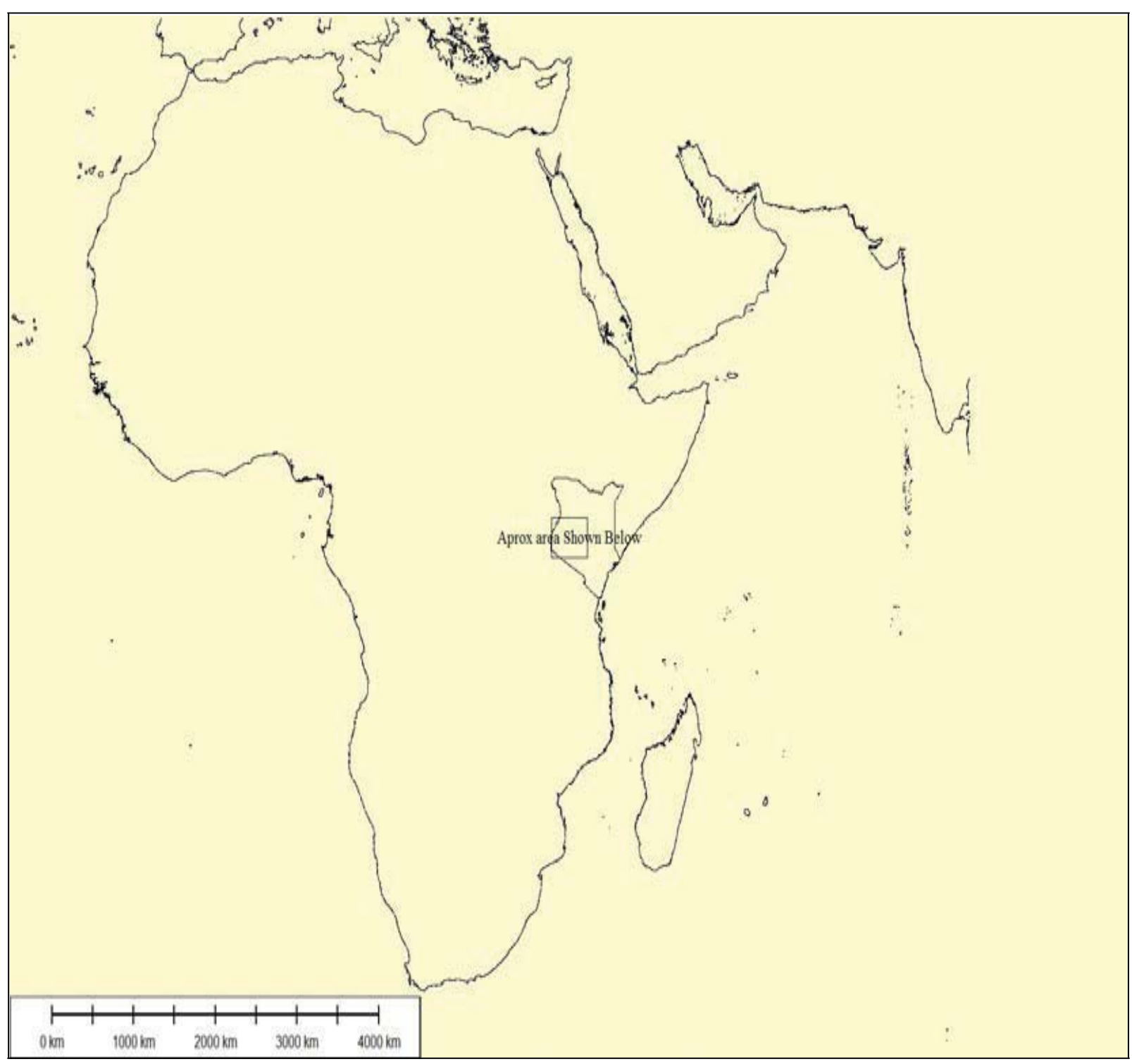


Figure 3: Map Showing the Traces of Faults Mapped for This Study Western border of Kenya on left

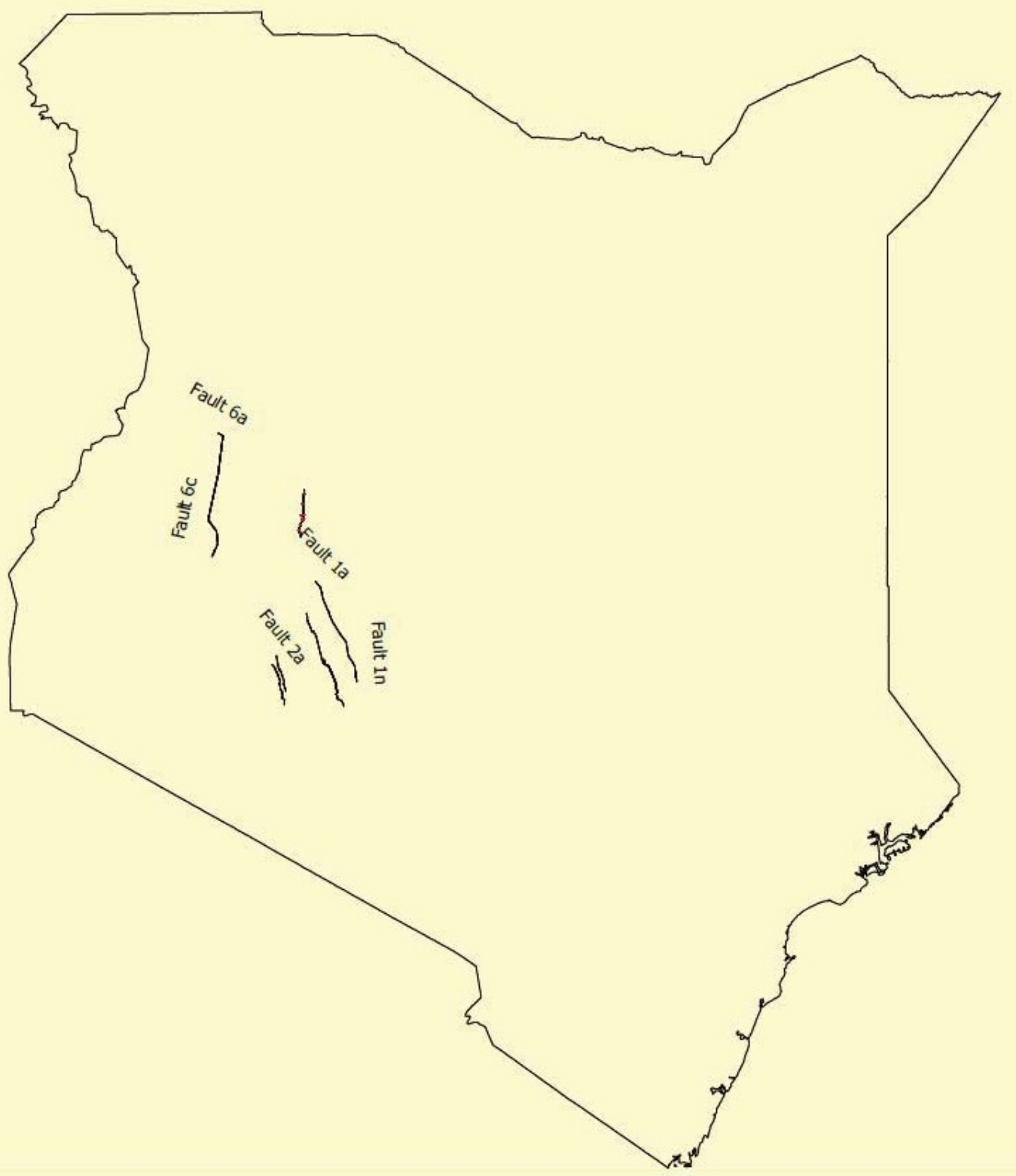


A secondary long term purpose of this report is to use the methods developed to examine the morphology of fault scarps within the Rift Valley for similarities in how they are aging/eroding in hopes of gaining insights into the geologic history of the rift. This is an aspect of the Southern Kenyan rift valley that has not received much attention with the exception of recent work by Gloaguen et al. 2007 and Sequar, 2009 , both of whom used remote sensing for classifying general geological structure.

A detailed understanding of how these features erode and change over time could provide new insights into the rift's geologic history, perhaps even leading to a better understanding of the sequence of the faulting events that define the southern rift. If the scarps were found to trend towards a given end state of erosion, then their relative "distance" from this state could speak to their relative age (i.e. a "pristine" fault that is close to its original post-movement state could be assumed to be younger and perhaps have seen more recent activity than one that was further along towards the theoretical erosion end-state.) This would provide insight into the sequence of faulting if faults with some orientations appeared older than others of a different orientation; the older orientation could represent an early stress state of the regional crust. It's also possible that the scarps could provide some indication of reactivation in later phases of the overall rifting sequence. In such a case, an initial period of movement on the fault would be followed by erosion during a period of quiescence before later reactivation of the fault. This quiescent period would have an impact on the geomorphology of the scarp. Most likely this would show itself in the scarp and show different ages across its profile. The larger overall profile of the scarp may reflect the original faulting and queasiest period of erosion, while the portion of the scarp nearest the fault itself would reflect the later reactivation and subsequent erosion.

Since the faults in this region have been measured as being relatively steep, $-70^{\circ}$ $80^{\circ}$, and thus significantly steeper than the angle of repose, it's likely that scarps would have two different slopes reflecting the different ages of the faulting events that 
created the slopes to begin with. These are the main concepts involved in this investigation.

As noted, the estimated slope angles of most of the faults in the study area have dips of $-70^{\circ}-80^{\circ}$. The general appearance of the landforms, including the horst blocks is illustrated in photographs in Figures $4 \mathrm{a}$ and $4 \mathrm{~b}$.

Figure 4a: Southern Kenyan Rift Valley

[Both pictures $4 a$ and $4 b$ are of the Southern Kenyan Rift Valley courtesy of Alexandria Guth]

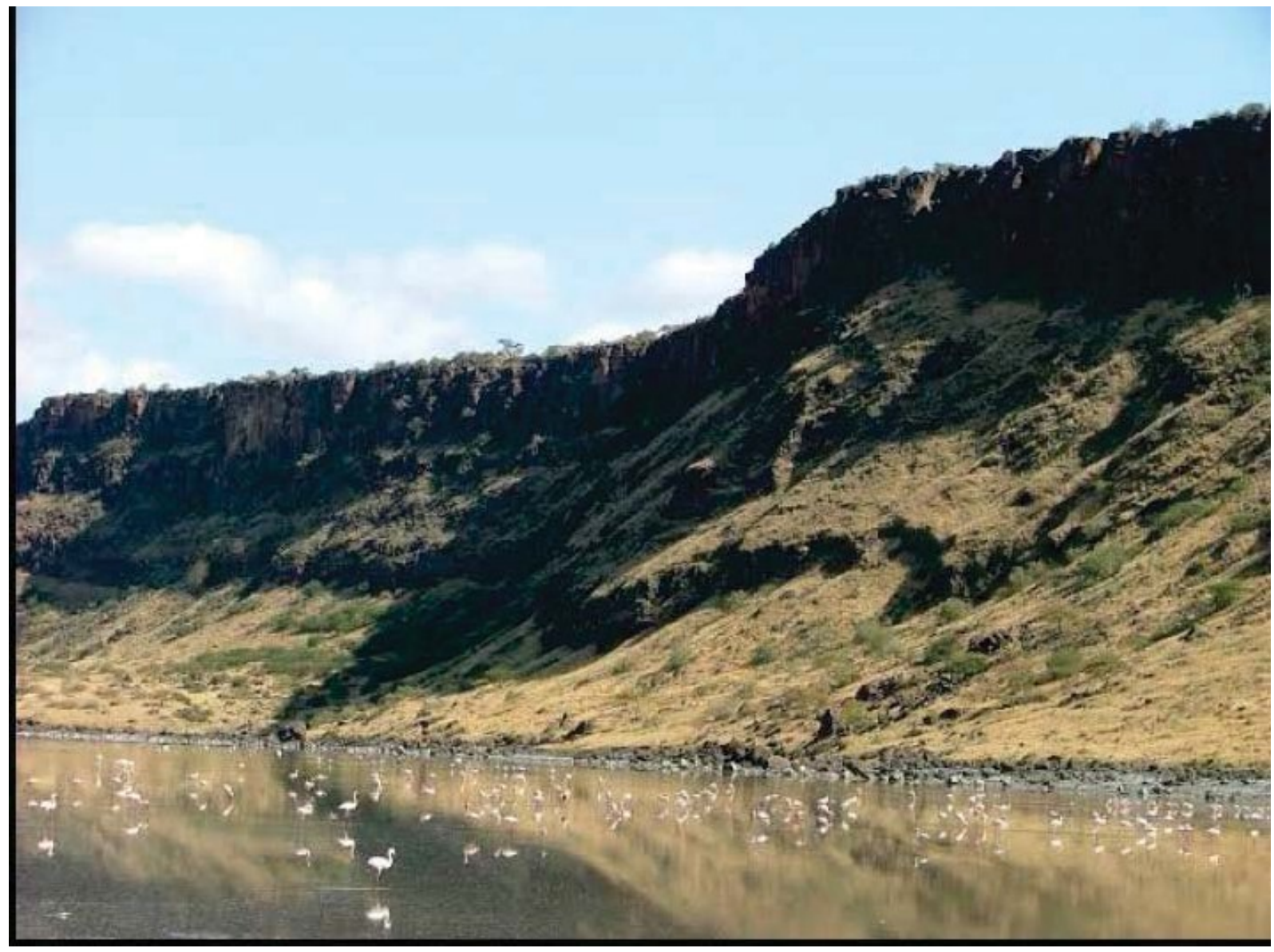


Figure 4b: Southern Rift Valley near Nairobi

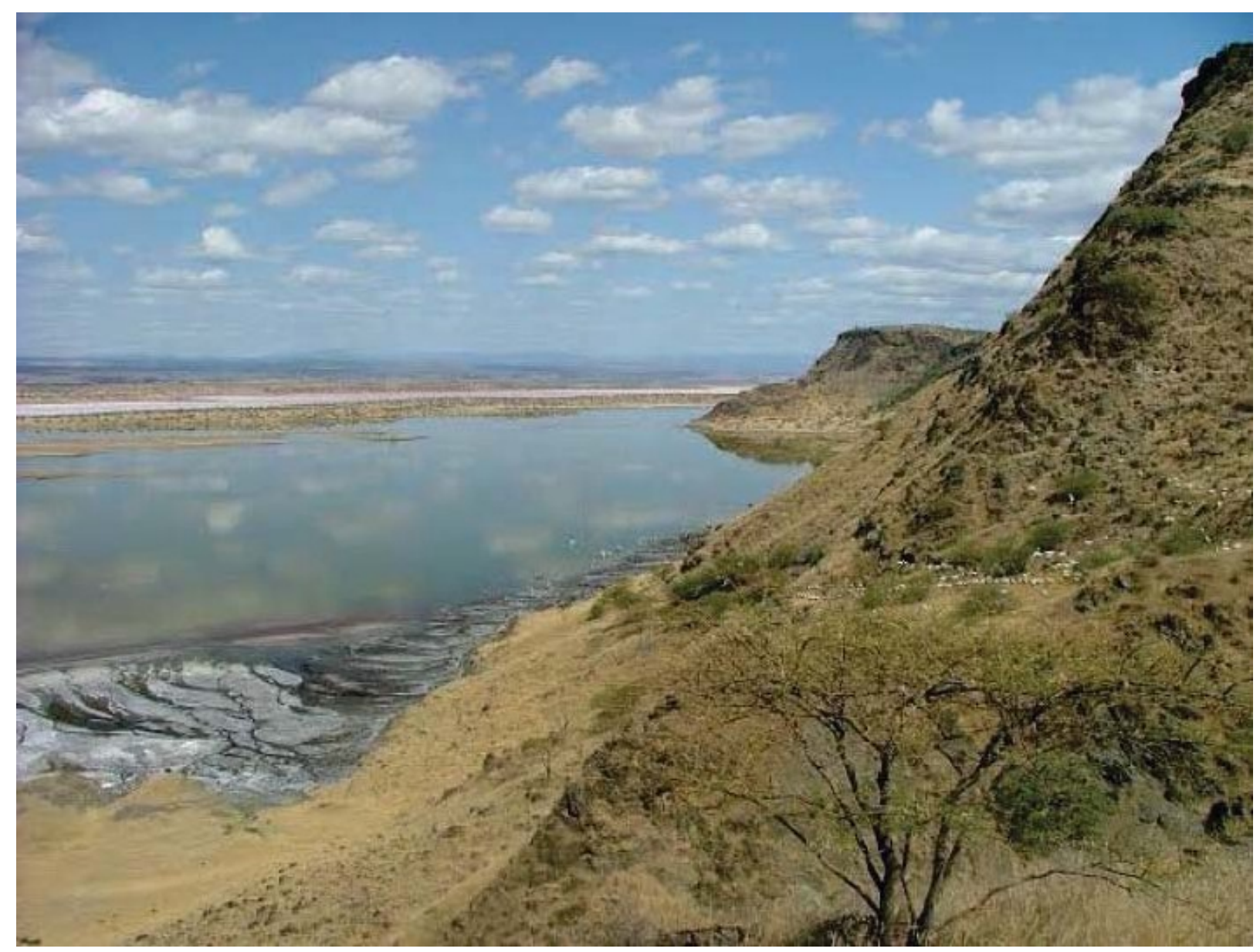

The geological and research background of the horsts blocks in this region will be described in the following section, followed by a description and discussion of how a remote sensing method was developed for studying fault profiles, prior to presenting data observation, interpretations, and findings.

\section{Geologic Setting and Background}

Rifts (areas where the Earth's crust is spreading or lengthening, and thus thinning) are one of the most spectacular features of global morphology. Within oceans they are locations where separate plates move apart (driven by convection within the Athenosphere) as new oceanic crust is created. Of all the world's rifts none can match in scale and diversity the Great Rift System, which runs for over $7000 \mathrm{~km}$ and includes the East African Rift System and its extension through the Red Sea into the 
Dead Sea, to form a unique feature of global geology. This forms (with the exception of Iceland) the only place on Earth where a Divergent Plate boundary can be accessed on land; where it is far easier to field work and conduct scientific investigation. The East African Rift system represent a fairly early stage in the evolution of such plate boundaries, including the thermal, magmatic, and tectonic processes which gave rise to them (H.G. Reading, 1986, p.1). Thus, It is one of the best examples of an active rift that exists today and has been used to interpret older, subsurface basins worldwide. (Frostick, 1997, p.187)

The Southern Kenyan rift represents a major part of the East African rift system. Baker (1987) identified three major stages in the tectonic development of the Kenyan rift:

(1) The pre-rift stage (30-12 Mya) with the forming of a depression and minor faulting

(2) The half-graben stage (12-4 Mya) with the forming of the main boundary faults, and

(3) The graben stage (4 Mya - Present) with an increase and an inward migration of faulting.

All stages were accompanied by intense, mostly alkaline, volcanism. However, almost all volcanoes of the Southern Kenyan rift are now extinct with some post volcanic hydrothermal activity in many places (M. Ibs-von Seht et al. 2008, p.69).

The Southern Kenyan rift valley consists of numerous fault blocks encompassing horsts, grabens and step-fault platforms that are very little modified by erosion (Baker, 1953, p.1). Fischer, Thomson, and Von Honhel in 1883 were the first Europeans to publish regarding expeditions to the Magadi area. They passed along the foot of the Nguruman escarpment in April, 1883 and noted the abrupt cliffs and banded terraces. In 1913, Parkinson described the fault escarpments and horsts or fault blocks in the Magadi region. (Baker, 1958, p.3) The soils on the lava horsts were described as generally thin and patchy. Since this era, the intensity of research in the area has waxed and waned over the succeeding decades, reaching a peak during the 1970 s and early 1980s when many of the most important hominid sites 
were found (Leakey et al. 1976).

The Kenyan rift valley raises formidable questions about the regions geologic history. Notably the Late Miocene and Late Pliocene to Mid-Pleistocene phases of dominantly phonolitic and trachytic activity coincided with periods of strong uplift of the Kenyan swell and with periods of rift-faulting. On the other hand, the Miocene and Pliocene basaltic volcanism occurred at times of comparative crustal stability. These features indicate a degree of interdependence of tectonic activity and volcanism that support the view that both processes are expression of surface changes in the upper mantle. (Baker, 1971, p.213).

As with all geological linear or curvilinear features, rifts are not the continuous simple features they appear to be when looked at from afar. They are invariably broken into segments by transverse features. The larger the scale at which they are seen, the more complex they become. Individual segments vary considerably in their structural style. Not only are rifts asymmetric in cross-section, but the direction of asymmetry appears to vary systematically along the rift, with the direction of asymmetry alternating between Eastern and Western Escarpments (Baker, 1988, p. 4). For a given age, length of faults, width of rift basins, relief of the uplifted rift flanks vary depending not on the age but on the stage of the rift segment (Chorowicz et al. 1987, p. 400).

One of the first remote sensing evaluations of fault blocks was conducted by Gloaguen et al. in 2006. This investigation showed that using radar, data on faults can be sufficiently detailed for the purpose of geologic mapping. This allowed an unbiased and fast counting of faults for further statistical analysis. However, faults were evaluated as sets of connected segments. The goal was to use this data to propose an evolution model for the growth, interaction and linkage of faults. (R. Gloaguen et al. 2007, p. 137) 
In 2009, Sequar used remotely sensed datasets along with other subsurface and surface data to characterize faults in the Lake Magadi area. Combined results of these datasets revealed four fault sets in the area. The existence of four set of faults having different styles and different relative ages suggested dynamic changes in tectonics of the Southern Keynan rift over time. (Sequar, 2009, p.1)

Thus, the value of remote sensing data for further exploring the geomorphology of the fault-bounded horst blocks in the Southern Kenyan Rift valley has been firmly established. This report develops and documents a new and up-to-date method for mapping fault segments, using remote sensing data and the digitizer tool in Global Mapper to create shapefiles of fault segments.

\section{Method Development}

The method devised uses MRSID LANDSAT images (available online at NASA's "Geocover" Website https://zulu.ssc.nasa.gov/mrsid) and SRTM (Shuttle Radar Topography Mission) elevation data available through Global Mapper's data download system. Combining this data together within Global Mapper 9 and 10 (the latter was released in 2010 while the research was underway) faults were digitized, breaking them up into straight-line segments using the digitizer tool. That is to say that any lineations with a significant slope were mapped as a single feature that zigged and zagged back and forth for as long as it continued.

\section{Original Method}

The original method used the topographic profile tool within Global Mapper to generate elevation profiles running perpendicular to the fault segments, saving the profiles as distance versus elevation text files (.xz). These files were then imported into Excel and saved after pasting in the "path details" from both the profile and a smaller profile that was used to take the fault scarp slope at the steepest point in full profile. Global Mapper's "path details" includes the "tilt" measurement which gives 
the slope of any profile made in the program. However, this measurement is taken from one end point to the other, making a second smaller profile necessary to measure from the steepest point. With this method, the slope has to be found by plotting the steepest part of the scarp (the part inferred to be a remnant scrap) in Excel and using Excel's trendline feature to get an equation for the trendline of the form:

$Y=m X+A$

Where: $\mathrm{Y}=$ elevation, $\mathrm{m}=$ slope, $\mathrm{x}=$ distance, and $\mathrm{A}=$ the starting elevation of the slope

Once this slope trend was determined, the inverse tangent can be computed to get the slope's angle in degrees, since $m$ is really just the tangent of the slope.

Unfortunately, this original method required that the slope be measured at several different points along the scarp profile.

An example of how this worked from a fairly typical fault in the Magadi area of southern Kenya follows on the next page. 
Figure 5: Method 1: Example of Breaking Fault Scarps Profiles into Segments Fault 1a Overall Method 1 Profile

All units are in meters throughout this paper

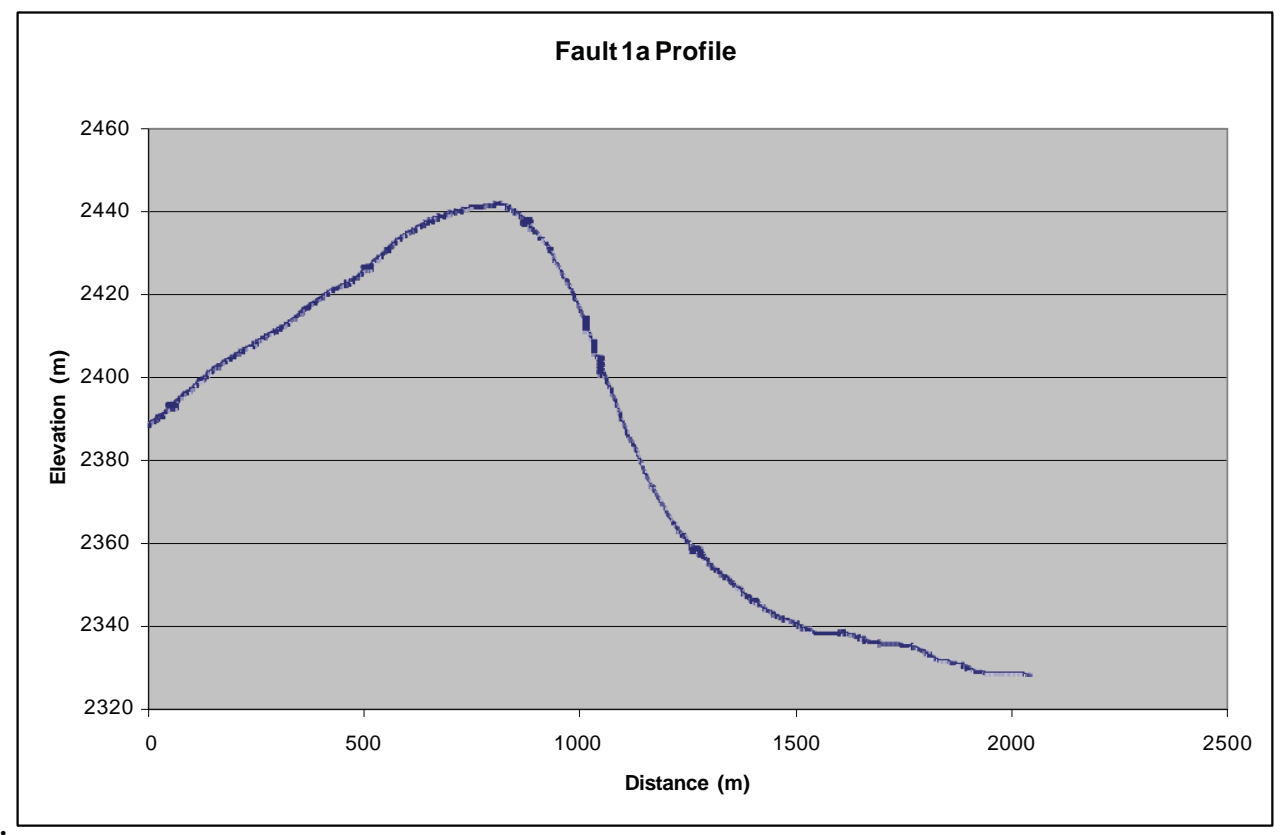

Starting with the distance/elevation files, these were exported into Global Mapper as ".xz" text files and then imported into Excel to generate the graph above. For this example, the slope on the uphill side of the fault (in this case. east of the fault) was detailed. This is slope segment 1. Slope segment 2 is the steepest part of the scarp itself and slope segment 3 is the debris pile that has built up at the bottom of the scarp. 
Figure 6: Method 1: Fault 1a Segment 1 Profile with Excel Linear Trendline

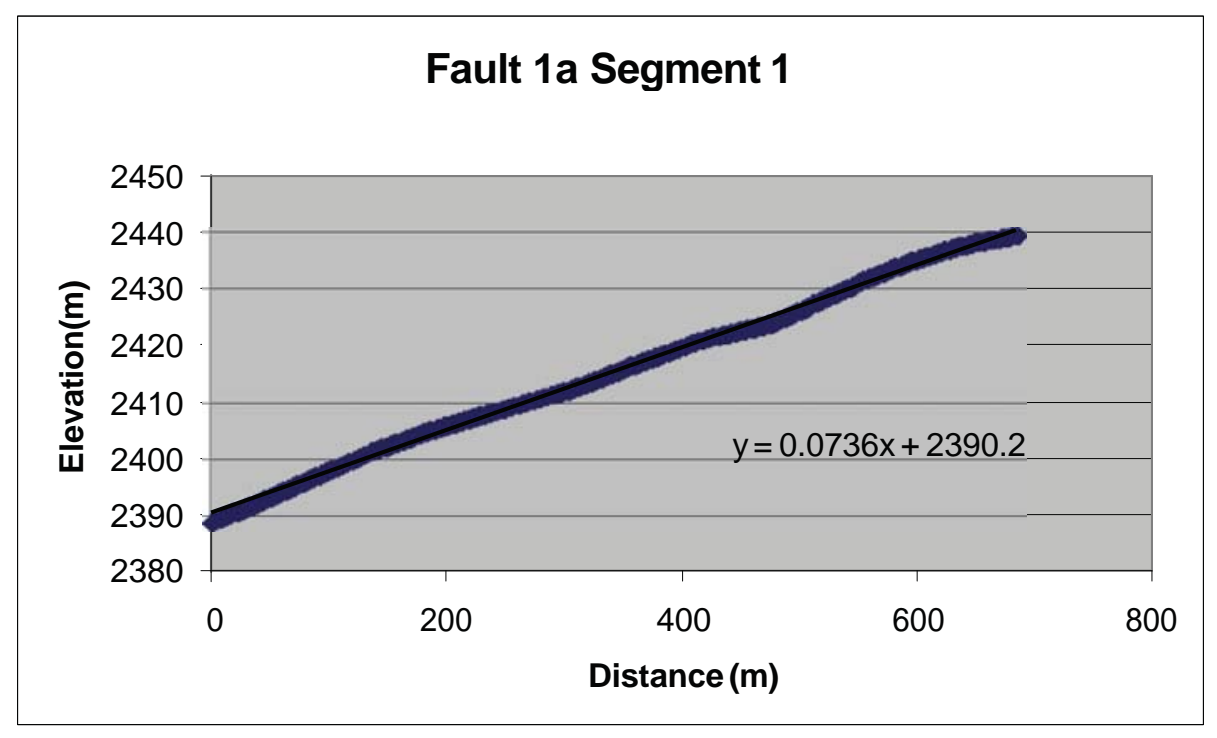

A linear trendline was then developed with its equation displayed. This was then converted into the trend line's slope in degrees using the following equation:

Excel formats its linear trendlines as:

$Y=$ slope ${ }^{*} X+$ Constant

The constant sets the line's vertical position on the graph:

Slope $=$ Rise/Run = tane (slope in degrees) therefore 8=Atan (slope)

For the Method 1 example above, Excel gives a trendline with a slope of 0.0736, so the calculations for slope segment 1 are as follows:

slope $=0.0736$

Tan8 $=$ rise $/$ run $=$ slope $=0.0736$

$\tan 8=0.0736$

$8=\operatorname{Atan}(0.0736)=4.20938^{\circ}$ 
Given that segment 1 was defined as being the top of the footwall block, a low slope of $-4.2^{\circ}$ seems reasonable. It should be noted that the dip of this slope is westward instead of being the eastward slope of the fault itself.

\section{$\underline{\text { Updated Method }}$}

To save the intensive labor required of Method 1, an updated method was developed as a part of this research that obtains the same result. Any linear fault scarp features observed were checked by taking a few profiles with the profile tool. If it looked like a legitimate fault (having a substantial slope associated with it), the digitizer tool was used to trace the fault (creating a shapefile). This is reasonably justified since most of the topography in the area is related to tectonic activity.

This revised process of data collection is the first to map out fault segments with the digitizer tool in Global Mapper (creating a shape file while giving the northern bearing of the lineation at the same time), and recording strike. A profile line (the overall profile) is then taken perpendicular to the fault segment, at a spot that is clear of noise like drainage patterns or large debris piles/alluvial fans. Using a secondary tool within the profile tool itself within Global Mapper, the slope of the scarp at its steepest point is then measured, since that is the point of most interest. The latitude and longitude of the point at which the profile crosses the segment is recorded as the location of the scarp.

Since the faults-strikes tend to "zig-zag", they were mapped as a single fault with several segments. This means that for a fault running $-180^{\circ}$, there will be second angles reflecting the jogs in the fault. This likely reflects the fact that what is being mapped as faults are more likely fault systems as oppose to individual faults.

The nomenclature system in the research data is to name a fault first by its area (i.e. Afar or Djibouti) or sometimes something distinctive about the fault (i.e.-Shaped Graben or Graben Area), then for its dip direction (i.e. E, W, SW, NE, etc.), then 
finally a number that is merely based on the order in which they were digitized. The bearing of the lines were then recorded as given by Global Mapper. As previously noted, west dipping faults had to be corrected by $180^{\circ}$ because of the way they were mapped in Global Mapper (always digitizing from North to South). Since Global Mapper always gives the bearing of a line from its starting point, it gave the bearing of all line measuring from the North. This means that it gives a bearing of $180^{\circ}$ for both a west or east dipping fault. This was corrected for by simply adding or subtracting $180^{\circ}$ depending on which was easier math-wise).

The last step in the data collection procedure was to use the profile tool within Global Mapper to take a profile perpendicular to each segment, measuring the slope of the scarp with a tool within the profile tool that allows for slope measurements. The slope of the scarp at its steepest point was measured and recorded. Again the scarp's location was taken to be the point at which the profile line crosses the fault. Decimal latitude and longitude of this point were recorded to the fifth decimal place.

\section{Results and Discussion: Data and Observations}

As the fault scarp profiles were examined using the updated method developed they began to clearly fall into categories based on their overall shape. The general trend seemed to be towards a sigmoid shape as is best typified by the profile of fault segment $1 \mathrm{a}$. 
Figure 7: Theoretical Model of Scarp Erosion--Fault 1a Profile

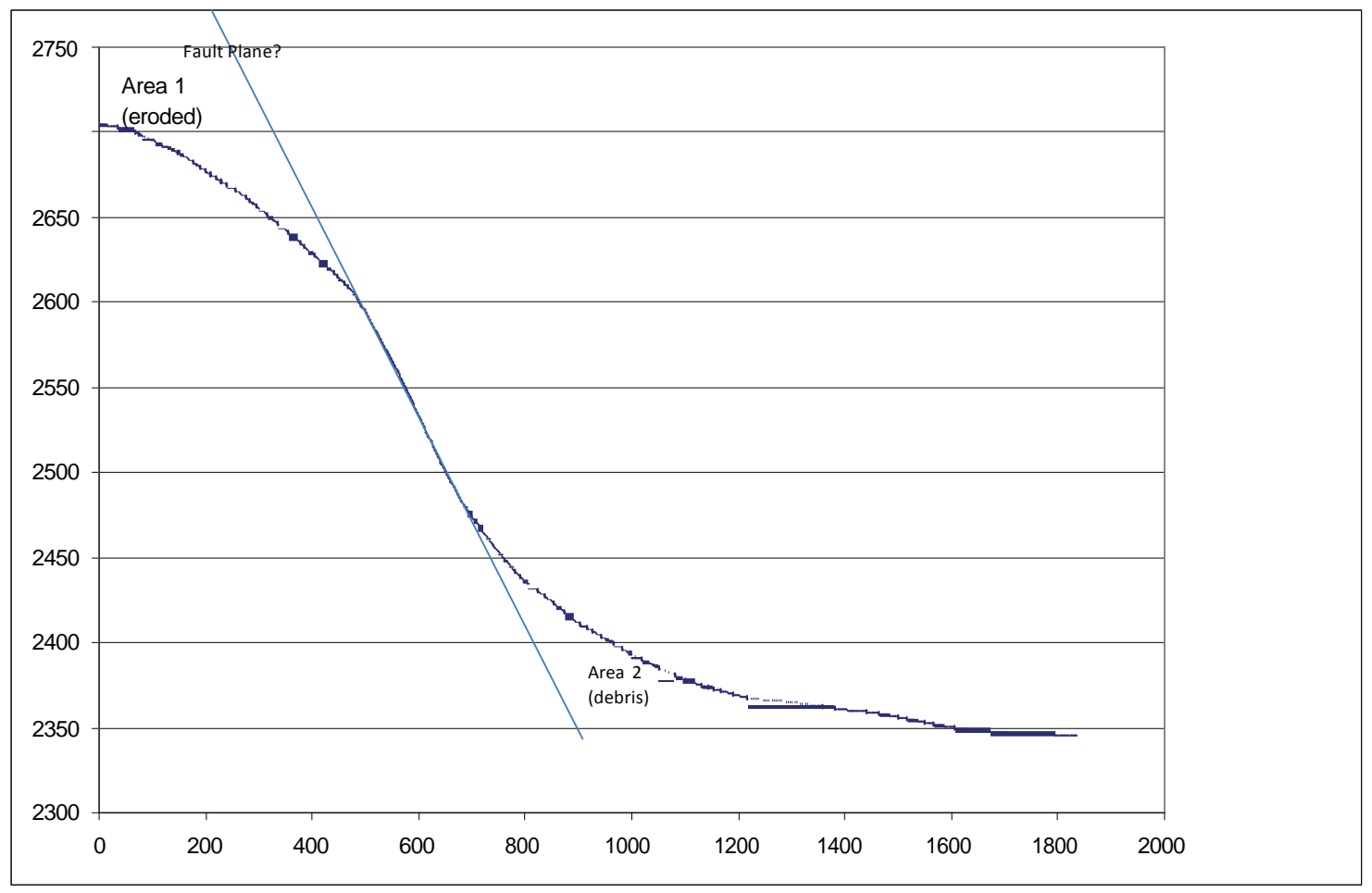

The prevalence of these sigmoid shaped profiles requires an explanation. The original state (its shape when movement stopped) of the fault scarps can be simplified to that of a "step" in which the horizontal parts represent the pre-faulting land surface and the angled portion represents the remnant of the fault itself as affected by erosion. The faults associated with the rift generally have a measured dip of $-70-80^{\circ}$ from horizontal. Assuming such an initial shape for the fault, taking into account that this is much greater than the angle of repose for loose gravel $\left(-30-45^{\circ}\right)$, it seems reasonable to assume that this original slope would erode in a sigmoid fashion. That is to say that material that gets eroded out at the top of the slope accumulates at the bottom of the slope in a debris pile or alluvial fan. This would naturally produce a sigmoid shaped profile over time as the scarp evolves and the original fault surface erodes. If this is the case, then the amount of material that is missing from the top (Area 1 above) should roughly equal the amount of material in the debris pile at the bottom of the scarp (Area 2 above), since the material that 
erodes out has to go somewhere and shouldn't have the energy to make it very far. Since a profile line is inherently 2-dimensional, this should mean that Area 1 approximately equals Area 2 . This provides an important constraint on these scarp profiles.

Other faults show features to be expected with abrupt cliffs; debris piles out beyond the bottom of the slope. A good example of this is provided by Fault 3J. See below corrected for Vertical Exaggeration. For a detailed discussion of vertical exaggeration and how it is corrected see Appendix A. 


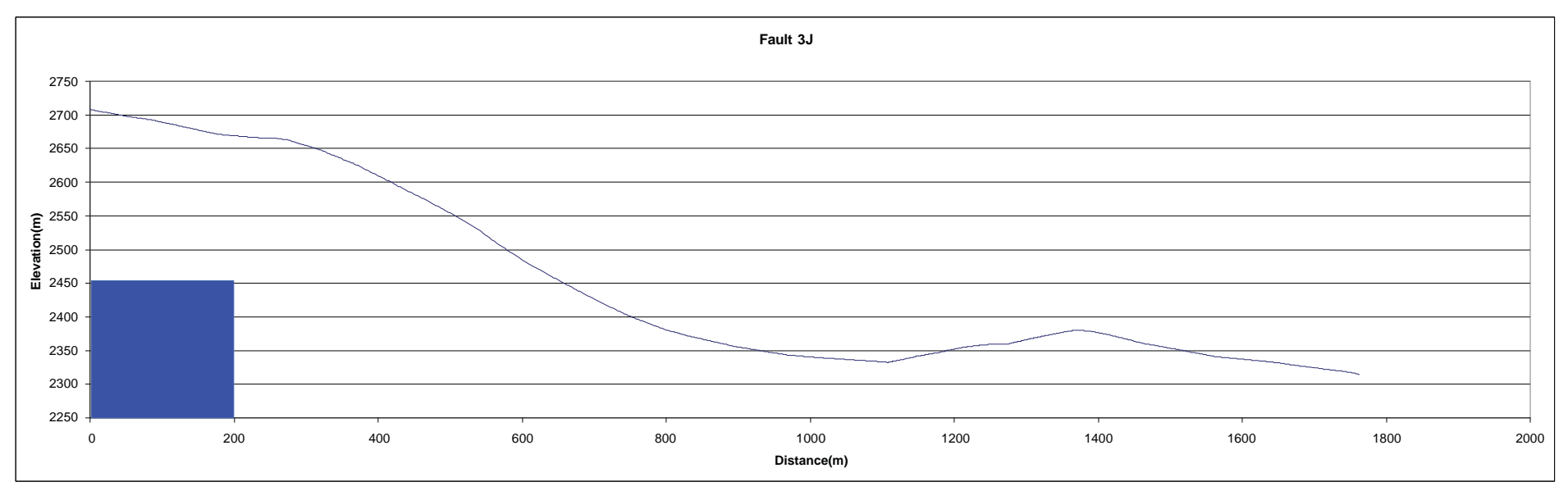


Given that the small rise around the $1400 \mathrm{~m}$ distance mark is beyond the slope of the scarp, it seems unlikely to be directly associated with the scarp. Given the sheer number of faults present in this region it seems likely that this small rise is another smaller fault within the floor of the rift. It should be noted that most of the faults observed were the major ones that define the Rift valley, forming the Eastern and Western Escarpments. There are many smaller faults within the valley floor with similar or even cross-cutting (perpendicular) strikes, but with much smaller displacement.

A few profiles show the odd character of being extremely crisp, appearing to be made up of only a few straight line segments. Fault 5 i seems to provide the clearest example of this. As Excel Originally drew it:

Figure 9: Fault 5i as Drawn by Excel: Original VE

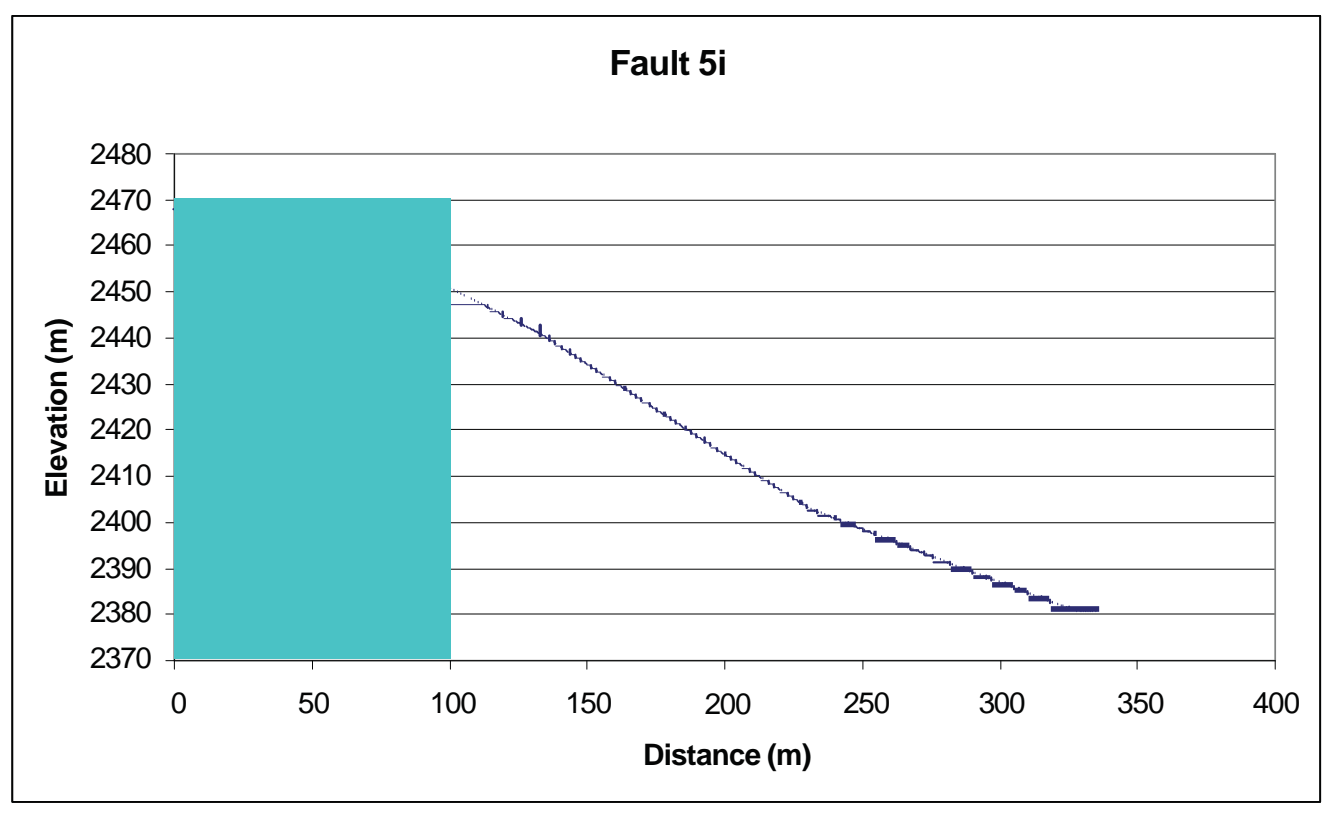

Given that this scarp has a smaller vertical drop than some of the others, a 100 meter square was used instead of the $\mathbf{2 0 0}$ meter square used elsewhere. In any case the vertical exaggeration (VE) isn't as big as in some of the other graphs.

Correcting for VE yields the graph below: 
Figure 10: Fault 5i as Drawn by Excel: Corrected for VE

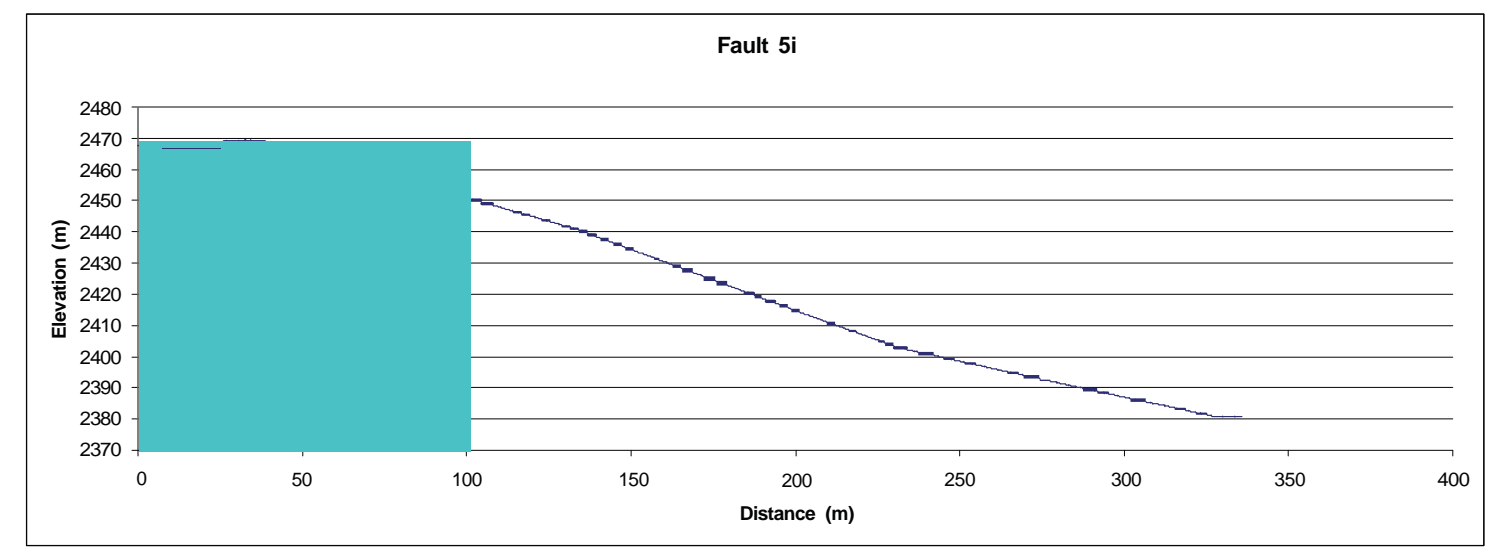

As can been seen, the profile appears to consist largely of straight line segments. The slope of the lines seems to follow the general sigmoid pattern in that the steepest one is in the middle of the scarp and the adjoining line segments are shallower. It actually looks very much like the opposite of the theoretical model of the scarps used in the first method. That is, breaking the scarp slope up into three slope segments; representing the remnant scrap in the middle with the erosion surface on the left and debris pile on the right. This scarp is likely in a fairly pristine state and perhaps relatively young and unchanged by erosion.

Another interesting profile morphology encountered is similar to the sigmoid shape but it has a large bump in it starting at about the mid-point of the scarp. The profile of Fault $2 \mathrm{n}$ provides the best example of this: 
Figure 11: Fault 2n as Drawn by Excel: Original VE

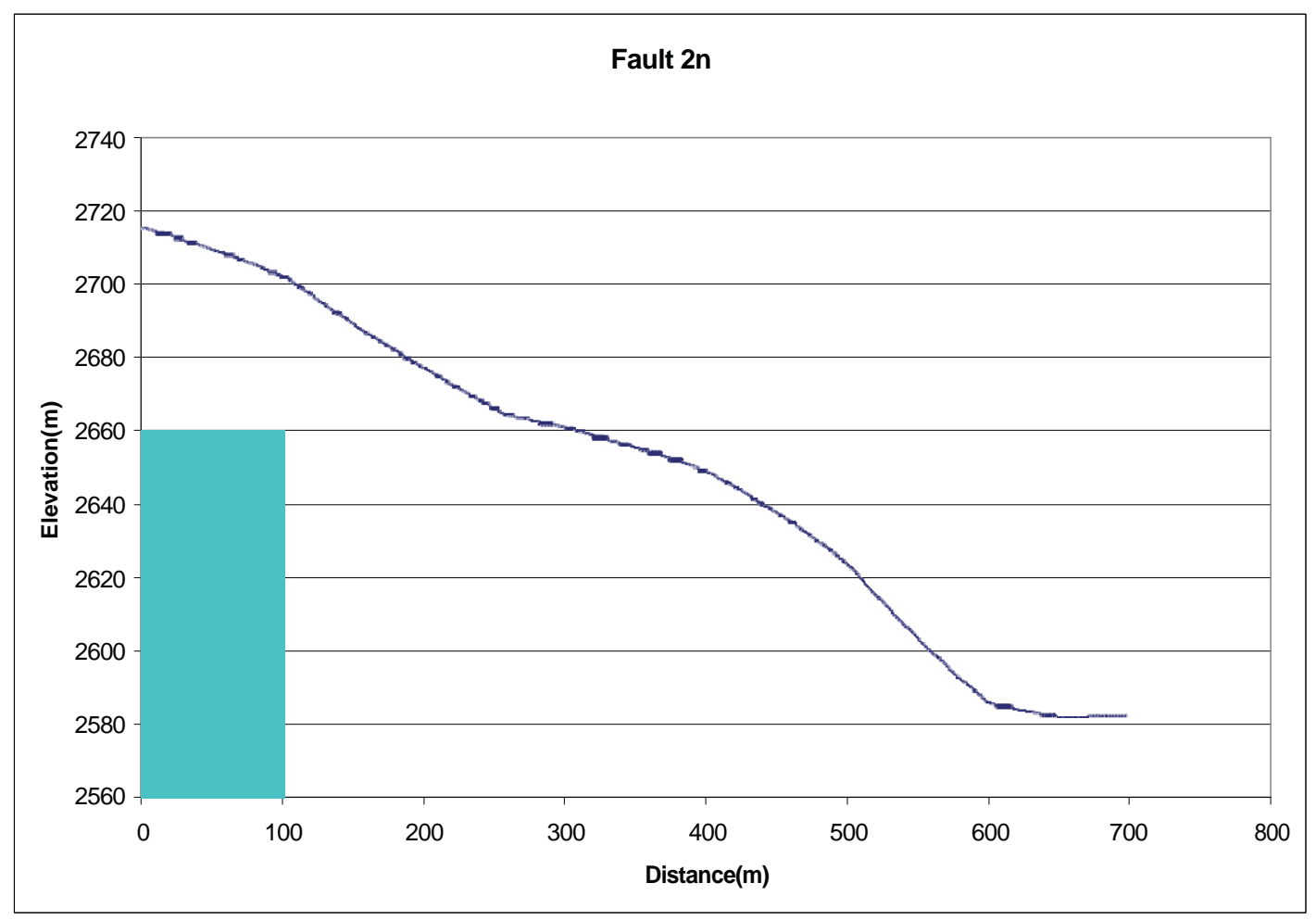

Figure 12: Fault $2 n$ as Drawn by Excel: Corrected for VE

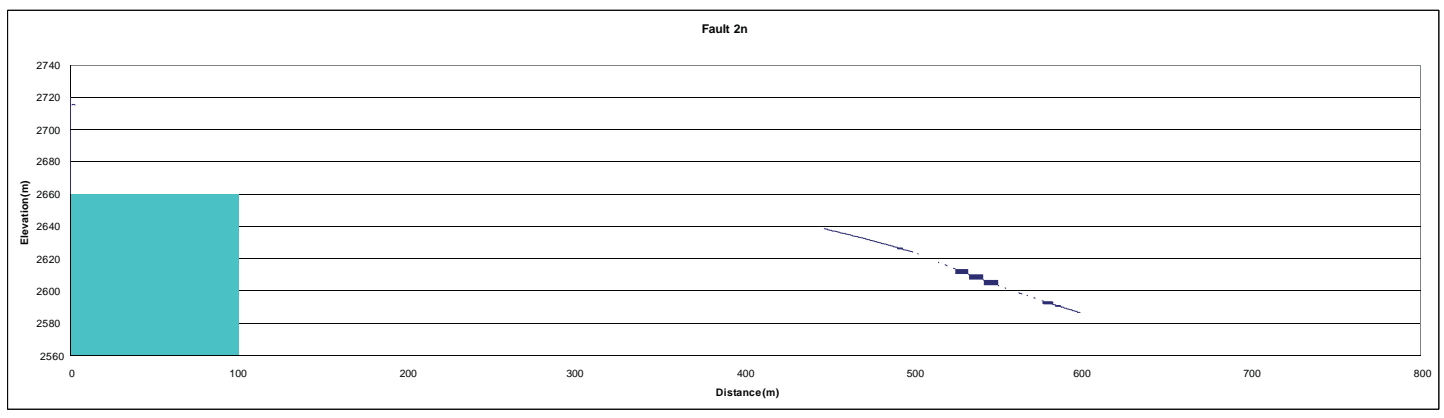

This one is a little harder to explain but appears very similar to scarps described in the Northern Sector of the Kenyan Rift by Bunkley et al. Looking at the Loriu Escarpment they argue for a sequence of events with two separate periods of faulting and two separate emplacements of lave flows. While the second lave flow is more specific to the area they were looking at, their explanation of that scarp seems to fit 
with what is seen in this profile. This implies faulting of the existing trachyte beds followed by a quiescent period during which the scarp was eroded back and then buried by extrusive volcanic material, followed by another period of tectonic quiescence in which the scarp eroded back into its present shape. Perhaps it's best to simply include their diagram of this process:

Figure 13: Buckley et al. Explanation of Development of Loriu Escarpment

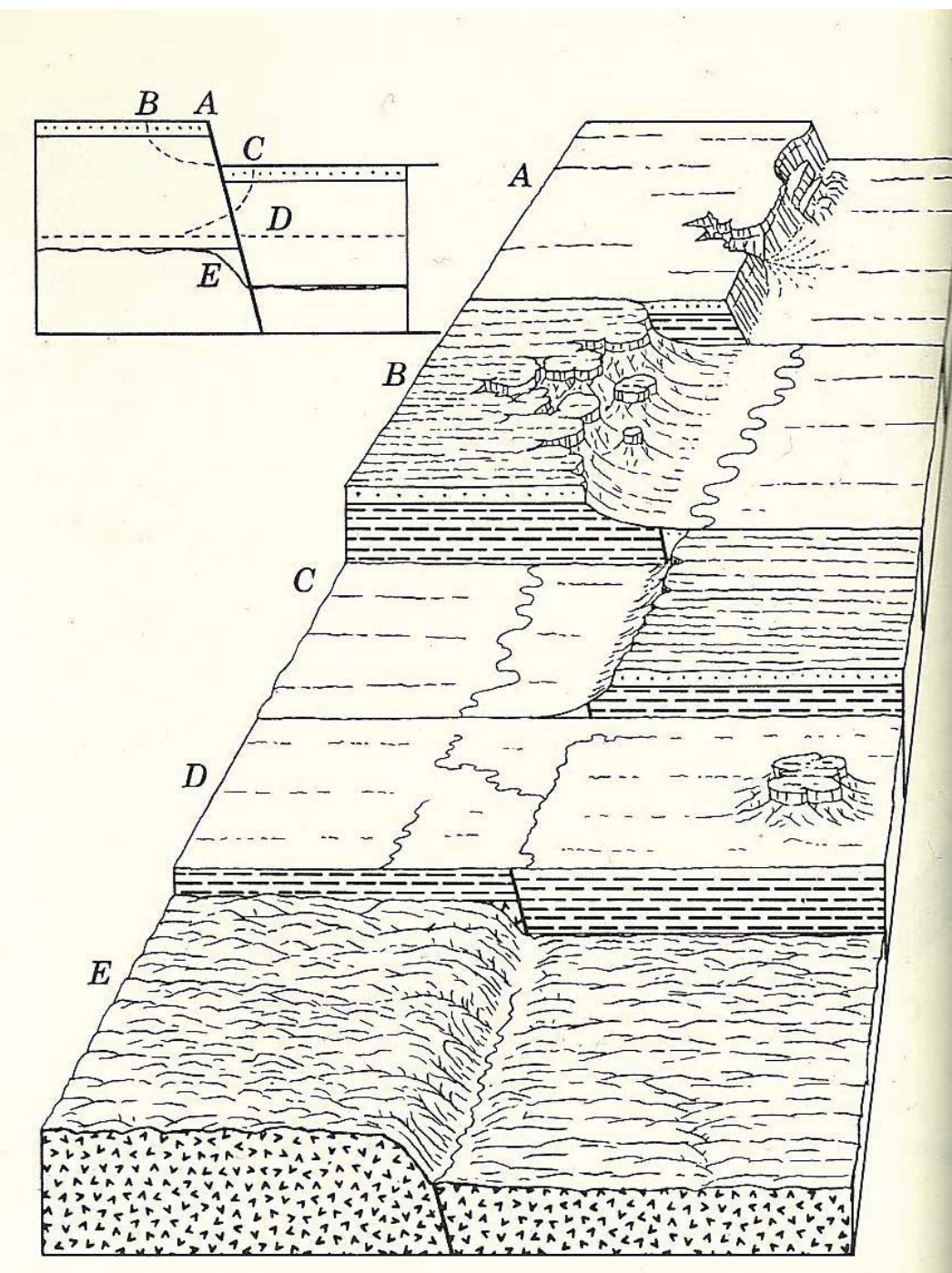

Figure 26.12 Development of a fault scarp and fault-lin scarps. 
As is explained in the accompanying text to this diagram in the book, this diagram assumes that the geology of the area around the fault consists of a resistant cap layer that has been worn away on the down-thrown side of the fault, underlain by a relatively easily eroded shale. That said, A shows a young fault scarp that still bears a reasonable resemblance to the original fault scarp after the cessation of tectonic activity on the fault; $B$ shows a more mature scarp in which the slope has eroded back from the original plain of the fault; $C$ shows the situation once a theoretical cap of resistant rock has been removed from the up-thrown side of the fault; $D$ shows the terrain reduced to a pene-plain; and finally $E$ shows the scarp re-emerging as the erosion surface reaches a resistant underlying layer of presumably crystalline rock. The cross-section in the upper left shows where these various erosion surfaces lie within the cross section.

As indicated, it is not clear whether there might have been a second or even more eruptions of material that covered the scarp after the first one, but this seems the most likely explanation for this profile shape. Figuring out the exact eruptive history of this scarp would require field work likely including the digging of a trench perpendicular to the scarp to see what the underlying geology is. Given that these are crystalline volcanic rocks, like basalt, this would likely require explosives to break the rocks apart and thus would be both time-consuming and potentially hazardous.

Some profiles seem to hint at the possibility of re-activation in other ways. They have a distinct bump in the middle of their slope. Fault $6 \mathrm{a}$ seems to provide a perfect example of this, as seen below: 
Figure 14: Fault 6a as Drawn by Excel: Original VE

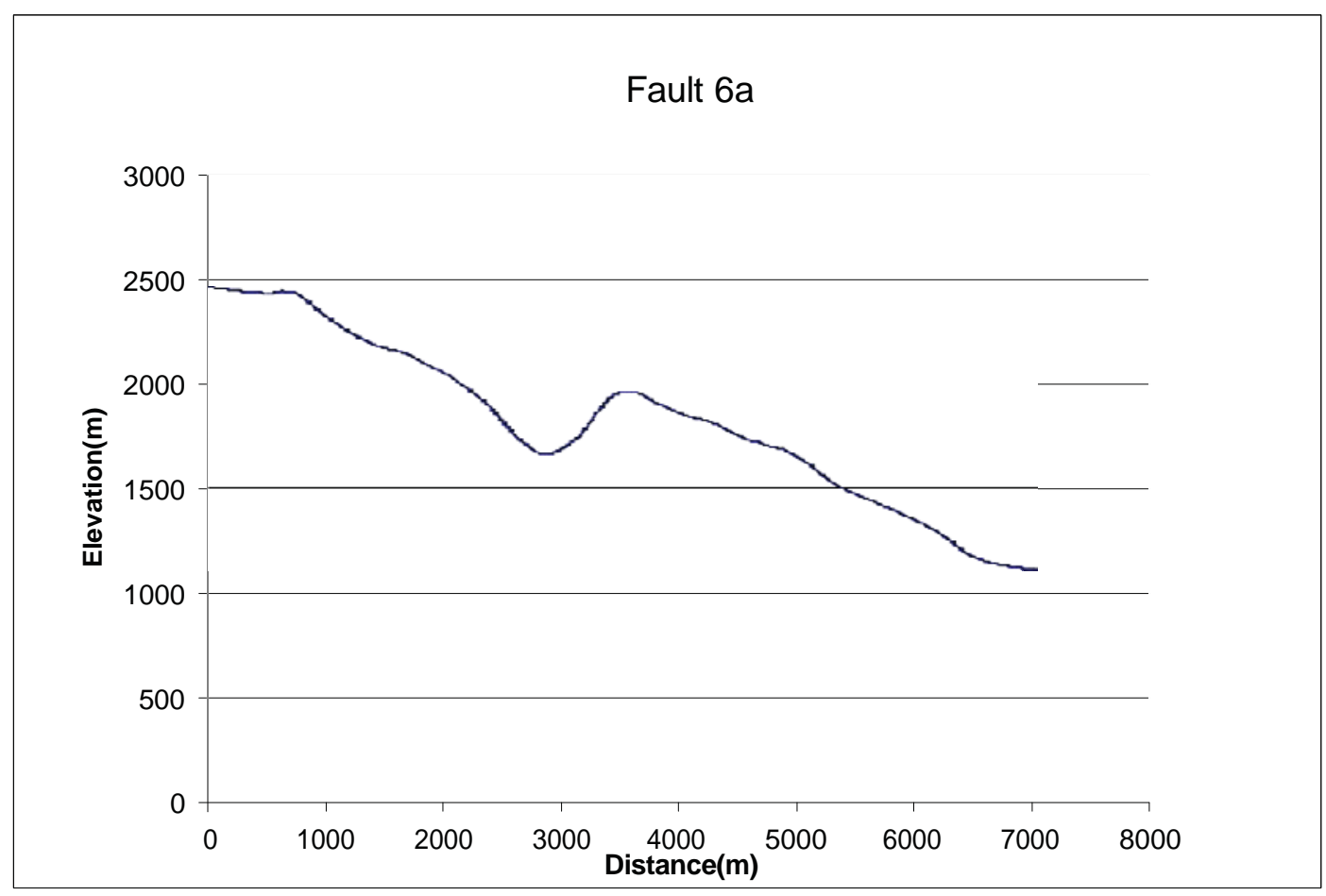

Figure 15: Fault 6a as Drawn by Excel: Corrected for VE

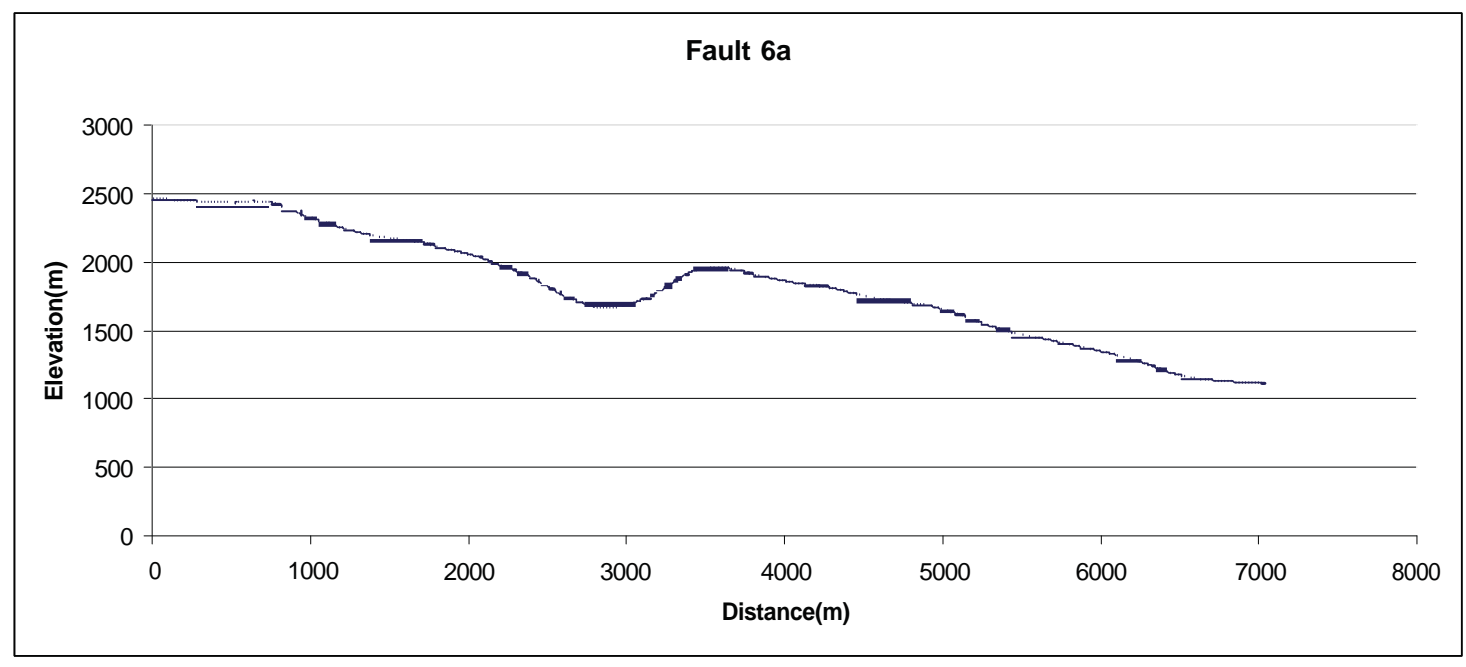


Figure 16: Fault 6a Possible Interpretation

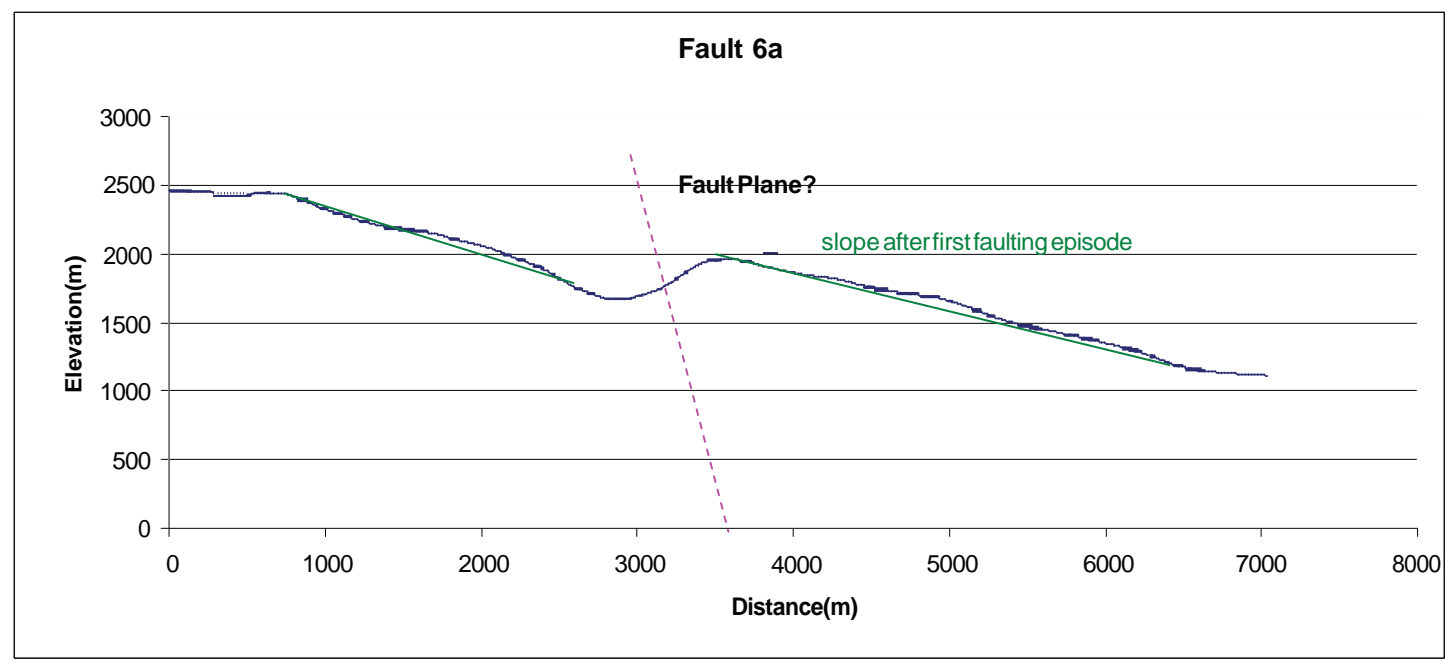

One possible explanation for the mid bump is that the slope may have been eroding back into the classic sigmoid shape when the fault re-activated, producing the bump. It must be remembered that visible scarps are unlikely to represent any part of the actual fault plane and may indeed have eroded back to the point that the fault itself is significantly displaced from the slope it created. However, in this case that displacement would be $3 \mathrm{~km}$, which seems unlikely. It's possible that this is actually a composite scarp made of two normal faults going in opposite directions (their strikes being $180^{\circ}$ apart from each other). In that case this bump in the main scarp would actually be a secondary scarp that dips in the opposite direction. The dips of the faults in this region have been measured and are generally $-70^{\circ}-80^{\circ}$ from horizontal (Baker et al.) In the first scenario, once activity on a fault stops it is left looking much like a step (i.e. very straight and crisp looking), the "vertical" portion of the step being the fault itself. This is often seen around the world after a large quake (but generally on a smaller scale); over time this crisp looking feature is eroded. Since these faults are known to be near vertical, typically $-70^{\circ}-80^{\circ}$ from horizontal, it seems likely that some of the material from the top of the original fault scarp would be eroded away and deposited at the bottom of the slope, leaving a debris pile. This would leave the original trace of the fault somewhere in the middle of the slope. This 
movement of material from the top of the original scarp to its bottom would naturally form a sigmoid shape over geologic time. If the fault were to become reactivated, one would expect to see something very much like what's seen above. That is, a slope somewhere between its original state and its final sigmoid shape with an interruption to the slope at the point the fault crosses it; with the results of the erosion of this new scarp below it.

Another general form of scarp profile observed in this research exhibited several bumps each with sigmoid-like slopes below them. This form is best typified by the profile of Fault 6e shown below as originally plotted in Excel:

Figure 17: Fault 6e as Drawn by Excel: Original VE

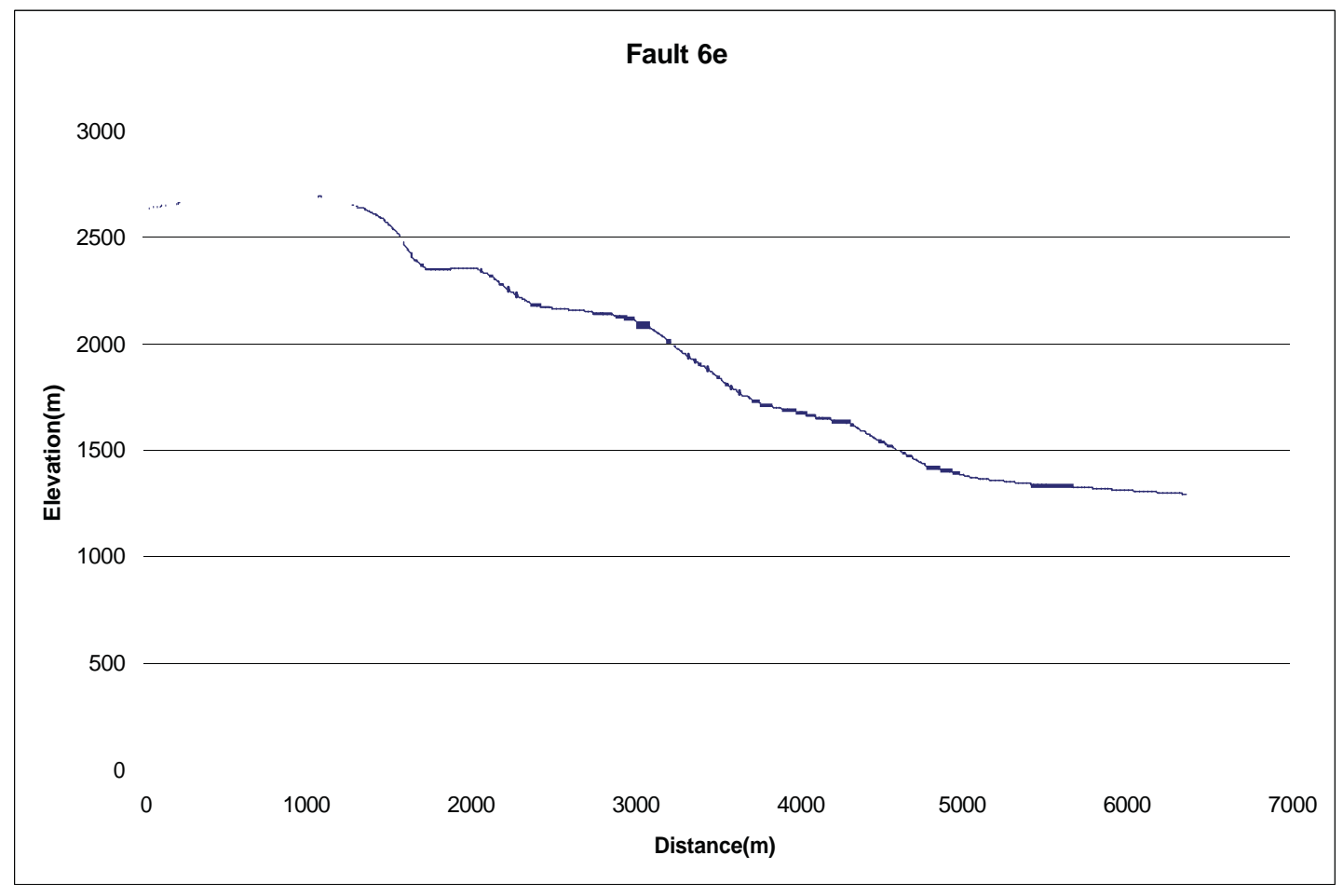


Figure 18: Fault 6e as Drawn by Excel: Corrected for VE

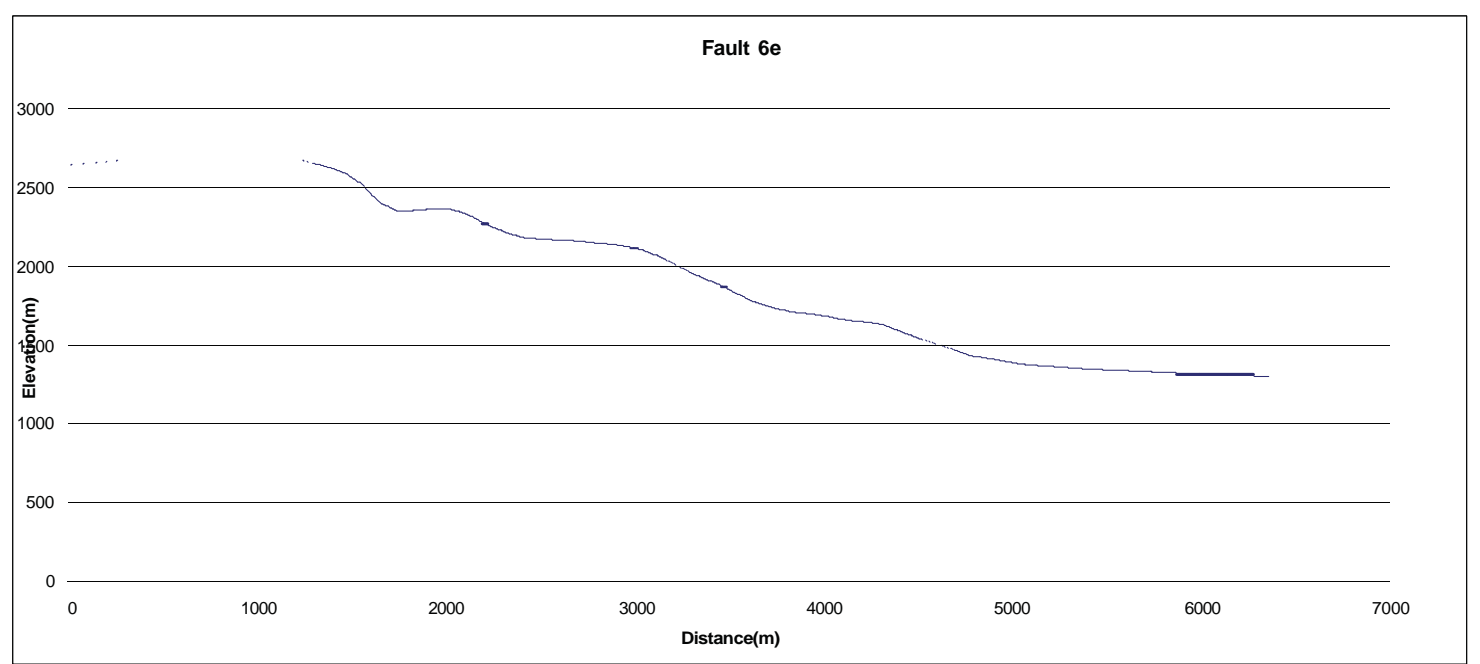

As previously stated, these faults were mapped assuming that any lineations that connected them were a continuation of the same fault and that these faults were largely singular drops (one large slope as opposed to multiple drops \& slopes). This doesn't appear to be the case for Fault 6e. The best explanation for this "rough and bumpy" profile, as it was originally dubbed, is that it is in fact multiple smaller faults instead of just one large one. In this scenario each bump in the profile would be tied to a different parallel fault. 
Figure 19: Fault 6e Possible Interpretation

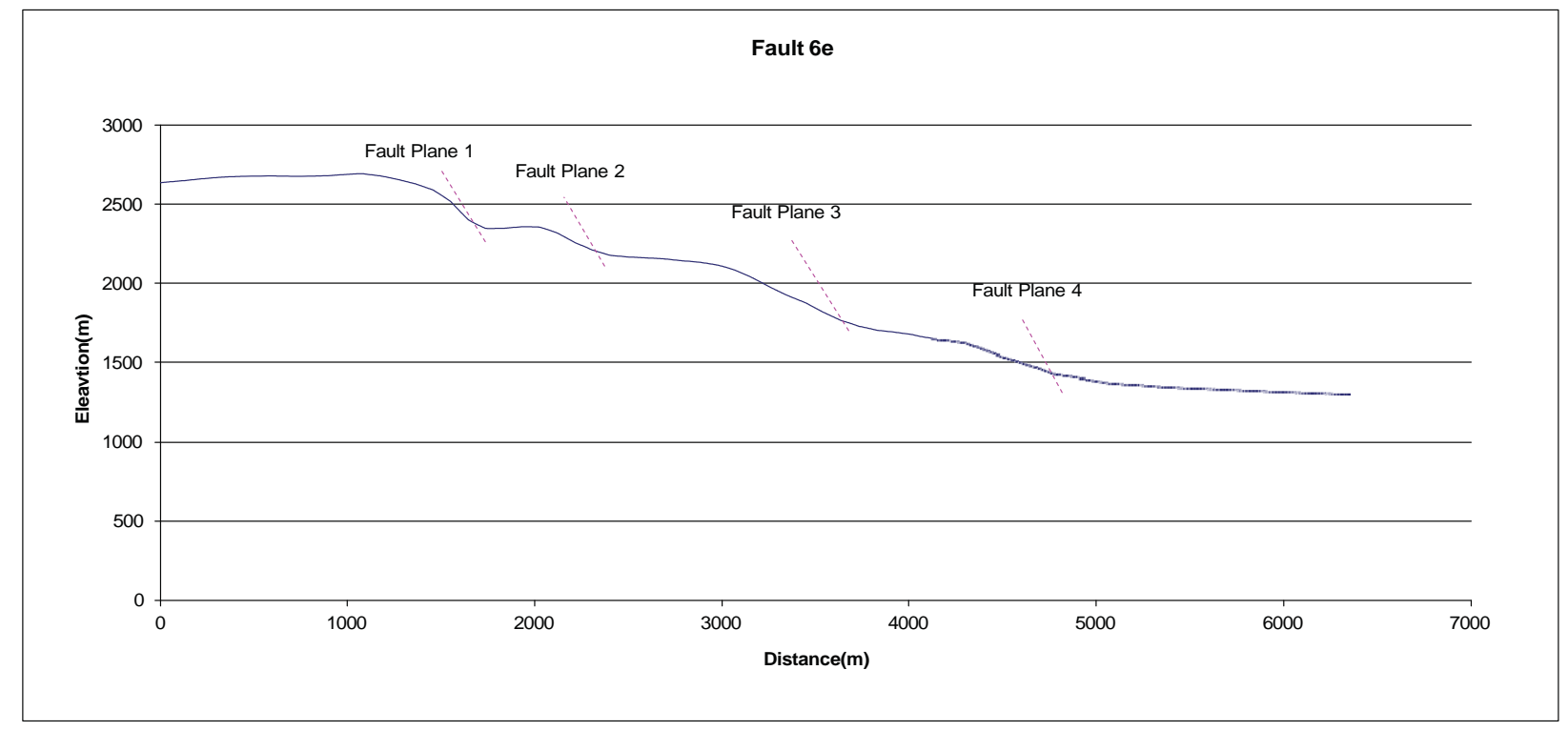

As can be seen the slope of the scarps decreases towards the bottom of the overall slope. There are alternative interpretations for this. The first, which is displayed in the above diagram, is that the dip of the fault planes is the same between all four scarps, but the scarps differ in age and thus stage of erosion (i.e. the lower slope seen in the lower faults simply reflects the fact that they are older and thus have been eroding longer). This would also be consistent with the general dip observed for faults within the rift. Another alternative interpretation is that the dip of the faults changes between the faults, starting at $-70^{\circ}-80^{\circ}$ near the top of slope and dropping to $-30^{\circ}-40^{\circ}$ by the bottom most fault. Still a third possibility is that this is a listric fault system with a series of faults with decreasing dips going from left (West) to right (East).

\section{Limitations of Research and Future Work}

Some of the limitations of this remote sensing method of observing faults should be noted. It must be remembered that the elevation data used is based on distance measurements taken from directly overhead. This means that a truly vertical slope with a $90^{\circ}$ slope would only show up as a sudden elevation change along the strike of the slope. This can be worked around by simply assuming this to be the case whenever such a situation is encountered. 
The other limitation is within the data itself. It must be remembered that any DEM (Digital Elevation Model) is basically just a grid with a value for the elevation at each point on the grid. A DEM can also be thought of as a three dimensional (3D) plot in with each $X, Y$ point has a corresponding $Z$ value representing the elevation. This creates a two dimensional surface within the 3D plot that represents the terrain in the real world. This comes, in part, from the way in which the elevation data was collected to begin with. The data is built up by taking distance measurements from orbit. This is done by beaming either a radar beam or laser down at the surface.

The time it takes the spacecraft to receive the return signal from the ground is directly proportional to the distance as in the equation below:

Equation:

Distance=half return time (since the signal travel both there and back) $\mathrm{x}$ the speed at which the signal travel (for both laser and radar based systems this would be $c$, the speed of light, since both are a form of electromagnetic radiation aka. Light)

Since the attitude of the spacecraft is known to a high degree of accuracy, subtracting the distance to the ground (based on how long it takes for the signal to return) gives the elevation of the terrain below. These measurements are generally taken in a grid pattern with the resolution of the data being given as to how far apart these measurement points are and how accurate each point is. In the case of the SRTM (Shuttle Radar Topography Mission) data used, each point is accurate to within a meter or so and the points are about 100 meters apart. In relation to this research work, this means that a slope that is several hundred meters long will be defined by only the couple of points at which it was measured. However, this research only deals with the large-scale features of these scarps, so it should be well above the resolution limits of the DEM.

It should be noted that most scarps examined in this research appear to be the result of a sequence of events. These would include tectonic history including possible reactivation and erosional history such as mass-wasting events. Therefore, advanced and more detailed research is needed to categorize faults or fault 
segments by age of development when applying the sigmoid erosion theory hypothesized in this report.

Future work would, of course, begin with gathering "ground truthing" data, namely going out in the field and measuring faults and slopes analyzed using this remote sensing based method, to determine if traditional field methods such as brunton compass support the findings of this remote sensing based method. Given the expense involved in traveling to Kenya to measure these particular scarps, this methodology could also be tested more locally, by using it to measure locally accessible slopes around the Keweenaw, where a similar rifting event occurred around a billion years ago. If the same method measures those slopes accurately, then it's reasonable to assume that it measured the Kenyan slopes accurately as well.

Once the "ground-truthing" is accomplished, the next logical step would be to do a broader census of fault scarps within the rift to see if the above patterns hold more broadly throughout the East African Rift or perhaps even beyond (to fault scarps more generally around the world).

\section{Conclusions}

As to scarp observation, the vast majority of the fault scarps examined in this report fell along a spectrum running from rough and shape-edged profiles indicating more recent or active scarps to more sigmoidal profiles with each having its own subtle eccentricities (most likely due to the anomalies of erosion such as the particular way the bedrock breaks or an especially large landslide, or a sequence of events). This would indicate that the scarps tend towards this state. This sigmoidal profile would thus represent a fairly stable end-state for the erosion of these scarps.

The erosive forces on a scarp are driven by gravity; rocks and debris roll downhill and stop rolling when the slope flattens out. This means that material eroded off the upper portion of a scarp piles up at the bottom of the slope over time. Eventually the slope of the debris pile, accumulating from the erosion of the upper portion of the scarp, meets. At this point, the entire slope will be below the angle of repose and 
stable under gravity, and thus there is no longer any force driving erosion. As the method and observations in this report show, many of the fault profiles are variations on the basic sigmoidal shape or are sigmoidal-shaped profiles that have been modified through subsequent tectonic activity.

The observation method developed in this report, based on readily available remote sensing data, can provide further evidence to support the notion that sigmoidalshaped profiles represent a natural endpoint of the erosional process of fault scarps. If the sigmoidal shape is indeed an erosional end-point then one would expect these shapes to be abundantly represented in a region such as the Southern Kenyan portion of the East Africa Rift Valley. Over time, faults of many different ages exist within this area. However, keeping in mind that other processes can be at work on scarps--most notably drainage patterns, when anomalies are observed, reactivation in some form possibly has occurred. 
Bibliography

Dunkley, P.N., M. Smith, D.J. Allen and W.G. Darling (1993). "The geothermal activity and geology of the northern sector of the Kenya Rift Valley", British Geological Survey Research Report SC/93/1.

Baker, B.H. (1958). Geology of the Magadi Area. Degree Sheet 51, S.W. Quarter, pp. 1-81.

Baker, B.H. (1963). Geology of the Area south of Magadi. Degree Sheet 58, N.W. Quarter, Report 61, pp. 1-28.

Baker, B.H., L.A.J. Williams, J.A. Miller, and F.J. Fitch. (1971). Sequence and Geochronology of the Kenya Rift Volcanics. Elsevier Publishing Company, Amsterdam. Tectonophysics, Vol. 11, pp. 191-215.

Baker, B.H. and J.G. Mitchell (1976). Volcanic stratography and geochronology of the Kedong-Olorgesailie area and the evolution of the South Kenya rift valley. Geological Society of London, Vol. 132, pp.467-484.

Reading, H.G. (1986). African Rift tectonics and sedimentation, an introduction. Geological Society of London, Special Publications, Vol. 25, pp. 3-7.

Baker, B.H., J.G. Mitchell, and L.A.J. Williams (1988). Stratigraphy, geochronology, and volcano-tectonic evolution of the Kedong-Naivasha-Kinangop region, Gregory Rift Valley, Kenya. Geological Society of London, Vol. 145, pp. 107-116.

Frostick, L.E. (1997). The East African Rift basins. Elsevier Science, Vol. 3, Amsterdam. Pp.187-209.

Atmaoui, N. and D. Hollnack (2003). Neotectonics and extension direction of the Southern Kenya Rift, Lake Magadi area. Elsevier Publications, Tectonophysics, Vol 364. pp. 71-63.

Chorowicz, J. (2005) The East African rift system. Elsevier Publications, Journal of African Earth Sciences, Vol. 43, pp. 379-410.

Gloaguen, R., P.R. Marpu, and I. Niermeyer (2007). Automatic extraction of faults and fractural analysis from remote sensing data. Nonlinear Processes in Geophysics, Vol. 14, pp. 131-138.

Ibs-von Seht, M., T. Phenefisch, and K. Klinge (2008). Earthquake swarms in continental rifts - A comparison of selected cases in America, Africa and Europe. Elsevier Publications, Tectonophysics, Vol. 452, pp. 66-77. 
Sequar, G.W. (2009). Neotectonics of the East African Rift System : new interpretations from conjunctive analysis of field and remotely sensed datasets in the Lake Magadi area , Kenya Neotectonics of the East African Rift System : new interpretations from conjunctive analysis. Geolnformation Science, February Issue, Abstract, p.1. 


\section{Appendix A: Vertical Exaggeration}

Vertical Exaggeration (VE) is the ratio of the vertical scale to the horizontal scale when referring to elevation. It is often useful to exaggerate elevation data because it can make even relatively small features in the landscape stand out, making them easier to spot and easier to analyze. When dealing with elevation plots, it is crucial to keep VE in mind because the shape seen in the plot is not necessarily the real-world shape. The easiest way to calculate the vertical exaggeration of a profile is to measure the ratio of equivalent distance along the two scales with a ruler. The distance used for this does not matter as long as the same distance is measured along both scales. The VE of the profile is the vertical measurement over the horizontal measurement.

As an example, the Theoretical Model of a Fault Scarp as presented in Figure 7 in this report is shown again below with a box for VE Explanation

Figure 20: Theoretical Model of Scarp Erosion--Fault 1a Profile: VE Example

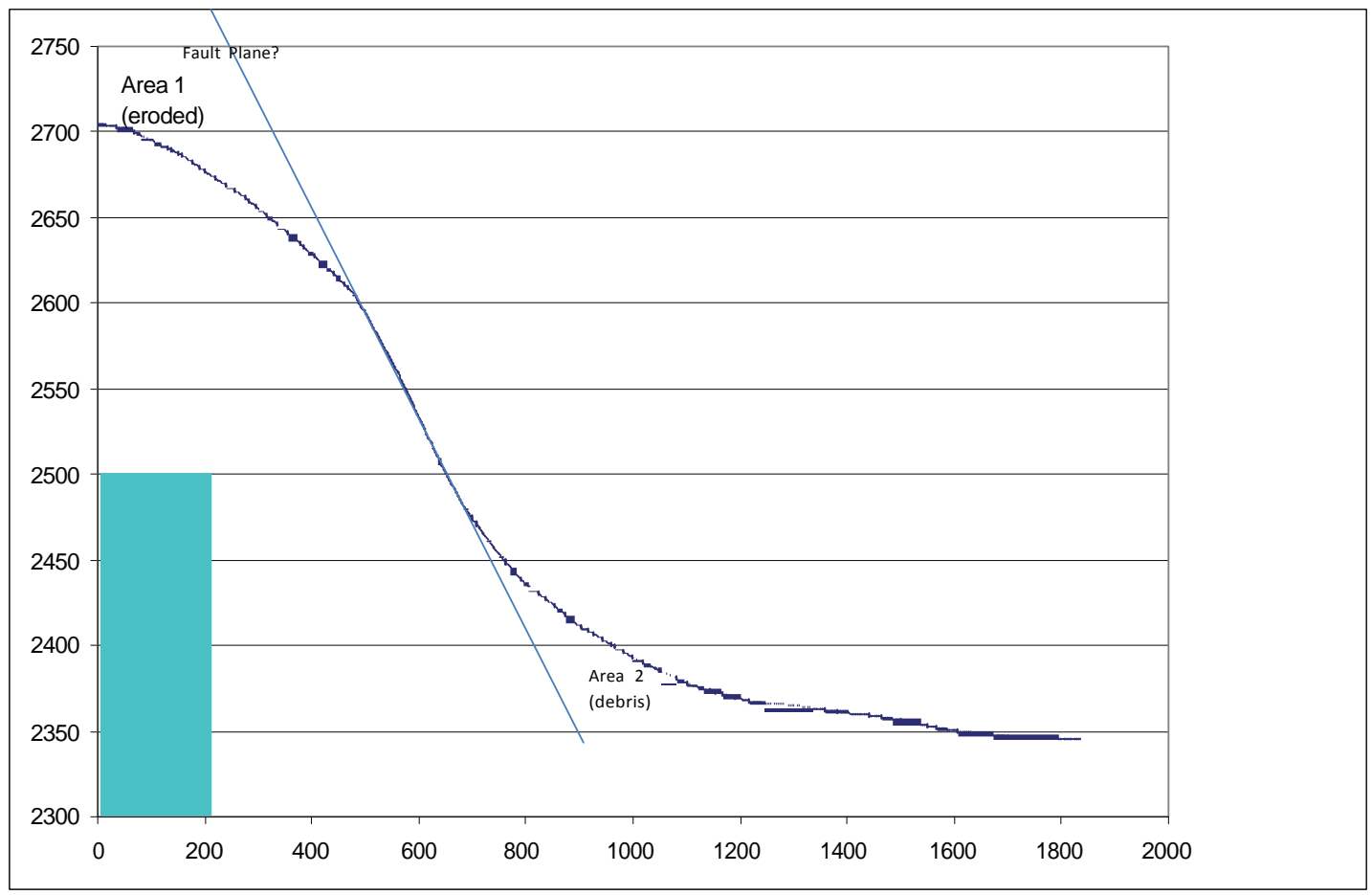


Taking this profile into account, it is apparent that the VE is substantial since the vertical scaling is substantially less than that of the Horizontal (a given distance on the horizontal scale represents a much large area in the real-world distance than that same distance does on the vertical scale).

In Figure 20, a box is drawn that covers an equal scaled distance on both of the axes. The transparency of the box is set to $75 \%$ in all graphs in this paper. The shape of this box is dictated by the ratio of the two scales (VE). The fact that it is a tall rectangle is indicative of the profile's substantial vertical exaggeration. If the profile in the graph had no VE, then its shape would be that of the real world scarp. In that case, its VE would be 1 and a box as drawn above would be a square since the 2 scales would be equal. Given this, the graphs can be played with in Excel until the box is square.

Since the graph starts out vertically exaggerated (stretched out of true in the vertical direction) this can be done one of two ways: either by stretching the graph horizontally or by compressing it vertically.

Stretching the graph horizontally, until the blue region is square, yields the following result:

Figure 21: Fault 1a corrected for VE

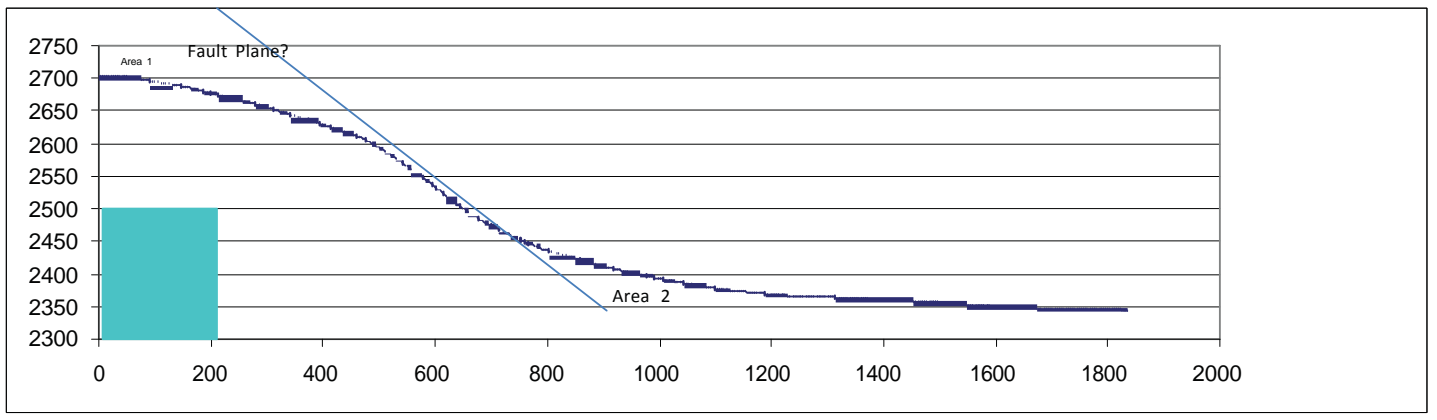


As can be seen this flattens out the slope, as well as exposes the fact that the putative fault plane line does not perfectly match up with the straight portion of the scarp.

The VE of any graph can be calculated as the ratio of the measure distance along each axis that represents a given scale length ("length in the real world"). If $\mathrm{VE}=1$ then by definition any given length will take up the same amount of measured space on the graph. In other words the two axis scales will be equal. The points at which these measurements are taken along each graph are inconsequential as long as the measure scale length is the same for both axes.

VE of graph=measured distance of vertical scale/ measured distance of horizontal scale

Measuring the vertical axis from 2300 to 2500 meters $(2500-2300=200)$ yields 4.1 $\mathrm{cm}$, while obtaining $1.2 \mathrm{~cm}$ along the vertical axis measuring from 0 to 200 meters $(200-0=200)$.

Plugging the numbers into the above equation:

$\mathrm{VE}=4.1 / 1.2=3.41678$

This means that all heights are exaggerated by an amount that is unique to each graph. If $\mathrm{VE}$ is greater than 1 then the profile looks much steeper than it is in the real world. Conversely, if VE is less than 1 then the graph's shape is flatter than it actually is. All of the graphs presented in this report have a VE substantially greater than 1; although each graph's VE differs slightly. 


\section{Appendix B: Excel Datasheet Containing Measurements}

\begin{tabular}{|c|c|c|c|c|c|c|}
\hline \multirow[b]{2}{*}{ Fault } & \multicolumn{6}{|l|}{ New } \\
\hline & $\begin{array}{l}\text { Naming } \\
\text { System }\end{array}$ & Segment & Strike & $\begin{array}{l}\text { Steepest Slope }\left({ }^{\circ} \text { from }\right. \\
\text { Horizontal) }\end{array}$ & Latitude & Longitude \\
\hline 1 & E1 & a & 139.9 & 13.3 & $0.032657 \mathrm{~N}$ & $36.394489 \mathrm{E}$ \\
\hline 1 & E1 & $\mathrm{b}$ & 163.2 & 6.5 & $0.018014 \mathrm{~S}$ & $36.426417 \mathrm{E}$ \\
\hline 1 & E1 & $\mathrm{c}$ & 171.3 & 16.3 & $0.067172 \mathrm{~S}$ & $36.437311 \mathrm{E}$ \\
\hline 1 & E1 & $d$ & 157.6 & 27.9 & $0.164725 \mathrm{~S}$ & $36.470681 \mathrm{E}$ \\
\hline 1 & E1 & $\mathrm{e}$ & 145 & 25.8 & $0.187347 \mathrm{~S}$ & $36.483489 \mathrm{E}$ \\
\hline 1 & E1 & $f$ & 170.6 & 31.3 & $0.211519 \mathrm{~S}$ & $36.483506 \mathrm{E}$ \\
\hline 1 & E1 & $g$ & 157.2 & 34.6 & $0.233933 \mathrm{~S}$ & $36.505491 \mathrm{E}$ \\
\hline 1 & E1 & $\mathrm{h}$ & 148.4 & 37.7 & $0.323064 \mathrm{~S}$ & $36.5454 \quad E$ \\
\hline 1 & E1 & i & 142.5 & 23.4 & $0.483508 \mathrm{~S}$ & $36.63675 \mathrm{E}$ \\
\hline 1 & E1 & $\mathrm{J}$ & 171.4 & 31 & $0.4870324 \mathrm{~S}$ & $36.636549 \mathrm{E}$ \\
\hline 1 & E1 & k & 161.6 & 30.7 & $0.5472817 \mathrm{~S}$ & $36.6475821 \mathrm{E}$ \\
\hline 1 & E1 & $\mathrm{L}$ & 145.9 & 30.5 & $0.579314 \mathrm{~S}$ & $36.664795 \mathrm{E}$ \\
\hline 1 & E1 & $\mathrm{m}$ & 152.8 & 31.2 & $0.62153929 \mathrm{~S}$ & $36.691011 \mathrm{E}$ \\
\hline 1 & E1 & $\mathrm{n}$ & 175.6 & 48.2 & $0.643986 \mathrm{~S}$ & $36.700000 \mathrm{E}$ \\
\hline 1 & E1 & 0 & 156.9 & 32.7 & $0.711344 \mathrm{~S}$ & $36.709244 \mathrm{E}$ \\
\hline 1 & E1 & $\mathrm{p}$ & 170.9 & 21.5 & $0.747847 \mathrm{~S}$ & $36.747847 \mathrm{E}$ \\
\hline 2 & W1 & $\mathrm{a}$ & 321.2 & 21 & $0.642741 \mathrm{~S}$ & $36.0485448 \mathrm{E}$ \\
\hline 2 & W1 & $\mathrm{b}$ & 354.3 & 31.3 & $0.662842 \mathrm{~S}$ & $36.0601179 \mathrm{E}$ \\
\hline 2 & W1 & c & 328.7 & 35.5 & $0.687056 \mathrm{~S}$ & $36.070461 \mathrm{E}$ \\
\hline 2 & W1 & $d$ & 341.6 & 14.3 & $0.707497 \mathrm{~S}$ & $36.081942 \mathrm{E}$ \\
\hline 2 & W1 & e & 325.4 & 27.8 & $0.732364 \mathrm{~S}$ & $36.09445 E$ \\
\hline 2 & W1 & $f$ & 349.7 & 19.7 & $0.732947 \mathrm{~S}$ & $36.593206 \mathrm{E}$ \\
\hline 2 & W1 & $g$ & 18.3 & 8.1 & $0.767353 \mathrm{~S}$ & $36.107078 \mathrm{E}$ \\
\hline 2 & W1 & $\mathrm{h}$ & 355.4 & 16.8 & $0.794428 \mathrm{~S}$ & $36.074869 \mathrm{E}$ \\
\hline 2 & W1 & $\mathrm{i}$ & 330.1 & 21.6 & $0.835464 \mathrm{~S}$ & $36.110061 \mathrm{E}$ \\
\hline 2 & W1 & j & 5.7 & 14.1 & $0.862364 \mathrm{~S}$ & $36.115491 \mathrm{E}$ \\
\hline 2 & W1 & $\mathrm{k}$ & 307 & 24.5 & $0.900053 \mathrm{~S}$ & $36.125567 \mathrm{E}$ \\
\hline 2 & W1 & I & 5 & 30.3 & $0.920363 \mathrm{~S}$ & $36.132467 \mathrm{E}$ \\
\hline 2 & W1 & $\mathrm{m}$ & 342.5 & 28 & $0.954169 \mathrm{~S}$ & $36.132569 \mathrm{E}$ \\
\hline 2 & W1 & $\mathrm{n}$ & 0.7 & 28.3 & $0.995456 \mathrm{~S}$ & $36.140628 \mathrm{E}$ \\
\hline 2 & W1 & 0 & 9.8 & 31.1 & $1.029125 \mathrm{~S}$ & $36.137167 \mathrm{E}$ \\
\hline 2 & W1 & $\mathrm{p}$ & 11 & 20.9 & $1.058458 \mathrm{~S}$ & $36.118705 \mathrm{E}$ \\
\hline 3 & E2 & $\mathrm{a}$ & 151 & 14 & $0.370639 \mathrm{~S}$ & $36.376039 \mathrm{E}$ \\
\hline 3 & E2 & $\mathrm{b}$ & 165.8 & 16.4 & $0.524556 \mathrm{~S}$ & $36.419578 \mathrm{E}$ \\
\hline
\end{tabular}




$\begin{array}{ll}3 & \text { E2 } \\ 3 & \text { E2 } \\ 3 & \text { E2 } \\ 3 & \text { E2 } \\ 3 & \text { E2 } \\ 3 & \text { E2 } \\ 3 & \text { E2 } \\ 3 & \text { E2 } \\ 3 & \text { E2 }\end{array}$

$\begin{array}{rc}125.3 & 23.9 \\ 154.6 & 22.2 \\ 156.8 & 20 \\ 177 & 22.1 \\ 158.9 & 17.1 \\ 205.9 & 9.9 \\ 163.3 & 30 \\ 119.5 & 34.1 \\ 173 & 21.9 \\ 350.2 & \\ 340.7 & 21 \\ 11.9 & 33.2 \\ 342.3 & 21 \\ & 38.5\end{array}$

$0.628208 \mathrm{~S}$

$36.468 \quad E$ $0.674233 \mathrm{~S} \quad 36.504958 \mathrm{E}$ $0.750719 \mathrm{~S} \quad 36.534478 \mathrm{E}$ $0.779508 \mathrm{~S} \quad 36.547194 \mathrm{E}$ $0.317531 \mathrm{~S} \quad 36.817467 \mathrm{E}$ $0.850442 \mathrm{~S} \quad 36.554523 \mathrm{E}$ $0.77795 \mathrm{~S} \quad 36.526239 \mathrm{E}$ $0.901606 \mathrm{~S} \quad 36.572089 \mathrm{E}$ $0.934444 \mathrm{~S} \quad 36.601244 \mathrm{E}$

$\begin{array}{lll}4 & W 12 & a \\ 4 & W 2 & b \\ 4 & W 13 & c \\ 4 & W 3 & c\end{array}$

5 E3 A

$5 \quad E 3$

5 E3

5 E3

$5 \quad E 3$

5 E3 $\quad F$

$\begin{array}{lll}5 & E 3 \quad G\end{array}$

5 E3 $h$

$5 \quad E 3$

$\begin{array}{lll}5 & \text { E3 }\end{array}$

5 E3 $k$

5 E3 L

5 E3 $m$

5 E3 n

$5 \quad E 3$

6 W3 a

6 W3 b

6 W3 c

6 W3 d

6 W3
A

C

D

E

F

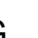

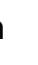

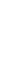

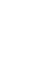

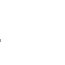

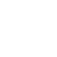

(n)

169.4

183.1

152.2

181.2

123.7

177.5

128.8

158

161.6

148.6

183.7

156.7

156.7

116.1

178.8

118.1

187.1

192.4

142.8

174.2

$$
\begin{array}{ll}
0.704581 & 36.110097 E \\
0.765033 & 36.129503 E \\
0.799786 & 36.135525 E
\end{array}
$$

0.2155944444

14.2

16.9

13.4

13.8

17.2

19.8

25.7

17.3

21.2

20.6

8.7

5.8

6.7

10.9

9

15.3

40.7

32.8

43.7

42.3
$\mathrm{S}$

0.2282138889

$\mathrm{S}$

$0.219580556 \mathrm{~S}$

$0.266316667 \mathrm{~S}$

$0.29433333 \mathrm{~S}$

$0.285588889 \mathrm{~S}$

$0.294158333 \mathrm{~S}$

$0.304763889 \mathrm{~S}$ 0.3230722222

$\mathrm{S}$ 0.3332416667

$\mathrm{S}$

$0.346861111 \mathrm{~S}$ 0.3499527778

$\mathrm{S}$

$0.353719 \mathrm{~S}$ 0.3528555556 $\mathrm{S}$

$0.358375 \mathrm{~S}$

1.2326972222

N

1.1116777778

$\mathrm{N}$

00.7598194444

$\mathrm{N}$

00.495972222

$\mathrm{N}$

00.4030777778
36.611577778E

36.312558333E

$36.313230556 \mathrm{E}$

36.316180556E

$36.318011111 \mathrm{E}$

36.3558472222

E

36.3267666667

E

36.3334166667

E

36.3407972222

$\mathrm{E}$

36.3451388889

E

$36.348611111 \mathrm{E}$

36.3487638889

E

36.3533719E

$0.35331762 \mathrm{E}$ 36.3574361111

E

$35.615075 \mathrm{E}$

35.7481694444

E

35.5611722222

E

35.5475138889

$\mathrm{E}$

35.5849777779 


\begin{tabular}{|c|c|c|c|c|c|c|}
\hline & & & & & $\mathrm{N}$ & E \\
\hline 6 & W3 & $f$ & 210.6 & 46.8 & $\begin{array}{l}00.3399972222 \\
N \\
00.3290888889\end{array}$ & $\begin{array}{l}35.590122222 \mathrm{E} \\
35.5866416667\end{array}$ \\
\hline 6 & W3 & $g$ & 185 & 41.1 & $\begin{array}{l}\mathrm{N} \\
00.3116633333\end{array}$ & $\begin{array}{l}\text { E } \\
35.3116333333\end{array}$ \\
\hline 6 & W3 & $\mathrm{h}$ & 213.6 & 39.2 & $\begin{array}{l}\mathrm{N} \\
00.2928722222\end{array}$ & $E$ \\
\hline 6 & W3 & i & 171 & 53.2 & $\begin{array}{l}\mathrm{N} \\
00.2762472222\end{array}$ & $\begin{array}{l}35.292822222 \mathrm{E} \\
35.2762472222\end{array}$ \\
\hline 6 & W3 & j & 213.7 & 52.2 & $\begin{array}{l}\mathrm{N} \\
00.2642027778\end{array}$ & $E$ \\
\hline 6 & W3 & $\mathrm{k}$ & 192.8 & 47.7 & $\begin{array}{l}\mathrm{N} \\
00.258325\end{array}$ & $\begin{array}{l}35.264027778 \mathrm{E} \\
35.5528944444\end{array}$ \\
\hline 6 & W3 & $\mathrm{L}$ & 234.9 & 17.3 & $\begin{array}{l}\mathrm{N} \\
00.2521333333\end{array}$ & $\begin{array}{l}\text { E } \\
35.3531333333\end{array}$ \\
\hline 6 & W3 & $\mathrm{m}$ & 200.3 & 15.7 & $\mathrm{~N}$ & $E$ \\
\hline 7 & E4 & $\mathrm{a}$ & 185.7 & 19.2 & $0.7513887 \mathrm{~N}$ & $36.2895428 \mathrm{E}$ \\
\hline 7 & E4 & $b$ & 183.2 & 38.8 & $0.6717276 \mathrm{~N}$ & $36.2480889 \mathrm{E}$ \\
\hline 7 & E4 & $\mathrm{C}$ & 178.3 & 33.2 & $0.58019961 \mathrm{~N}$ & $36.285513961 E$ \\
\hline 7 & E4 & $\mathrm{d}$ & 193.4 & 35 & $0.55116241 \mathrm{~N}$ & $36.284964 \mathrm{E}$ \\
\hline 7 & E4 & $\mathrm{e}$ & 233.3 & 32.8 & $0.53334679 \mathrm{~N}$ & $36.2767425 E$ \\
\hline 7 & E4 & $f$ & 200 & 38 & $0.5029628 \mathrm{~N}$ & $36.26236 \mathrm{E}$ \\
\hline 7 & E4 & $\mathrm{h}$ & 184.1 & 34.2 & $0.43658458 \mathrm{~N}$ & $36.2590084 \mathrm{E}$ \\
\hline 7 & E4 & $\mathrm{i}$ & 177.68 & 44.1 & $0.41986382 \mathrm{~N}$ & $36.26351055 \mathrm{E}$ \\
\hline
\end{tabular}




\begin{tabular}{|c|c|c|c|c|}
\hline 3 & E2 & $c$ & 125.3 & 23.9 \\
\hline 3 & E2 & $d$ & 154.6 & 22.2 \\
\hline 3 & E2 & $\mathrm{e}$ & 156.8 & 20 \\
\hline 3 & E2 & $f$ & 177 & 22.1 \\
\hline 3 & E2 & $\mathrm{g}$ & 158.9 & 17.1 \\
\hline 3 & E2 & $\mathrm{h}$ & 205.9 & 9.9 \\
\hline 3 & E2 & i & 163.3 & 30 \\
\hline 3 & E2 & $\mathrm{J}$ & 119.5 & 34.1 \\
\hline 3 & E2 & $\mathrm{k}$ & 173 & 21.9 \\
\hline 4 & W12 & $\mathrm{a}$ & 350.2 & 21 \\
\hline 4 & W2 & $b$ & 340.7 & 33.2 \\
\hline 4 & W13 & 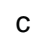 & 11.9 & 21 \\
\hline 4 & W3 & $d$ & 342.3 & 38.5 \\
\hline 5 & E3 & A & 169.4 & 14.2 \\
\hline 5 & E3 & $B$ & 183.1 & 16.9 \\
\hline 5 & E3 & C & 152.2 & 13.4 \\
\hline 5 & E3 & $\mathrm{D}$ & 181.2 & 13.8 \\
\hline 5 & E3 & $E$ & 123.7 & 17.2 \\
\hline 5 & E3 & $\mathrm{F}$ & 177.5 & 19.8 \\
\hline 5 & E3 & G & 128.8 & 25.7 \\
\hline 5 & E3 & $\mathrm{h}$ & 158 & 17.3 \\
\hline 5 & E3 & i & 161.6 & 21.2 \\
\hline 5 & E3 & $\mathrm{J}$ & 148.6 & 20.6 \\
\hline 5 & E3 & $\mathrm{k}$ & 183.7 & 8.7 \\
\hline 5 & E3 & $\mathrm{L}$ & 156.7 & 5.8 \\
\hline 5 & E3 & $\mathrm{m}$ & 156.7 & 6.7 \\
\hline 5 & E3 & $\mathrm{n}$ & 116.1 & 10.9 \\
\hline 5 & E3 & 0 & 178.8 & 9 \\
\hline 6 & W3 & $a$ & 118.1 & 15.3 \\
\hline 6 & W3 & $\mathrm{b}$ & 187.1 & 40.7 \\
\hline 6 & W3 & $\mathrm{C}$ & 192.4 & 32.8 \\
\hline 6 & W3 & $d$ & 142.8 & 43.7 \\
\hline 6 & W3 & $\mathrm{e}$ & 174.2 & 42.3 \\
\hline 6 & W3 & $f$ & 210.6 & 46.8 \\
\hline
\end{tabular}

$\begin{array}{ll}0.628208 \mathrm{~S} & 36.468 \mathrm{E} \\ 0.674233 \mathrm{~S} & 36.504958 \mathrm{E} \\ 0.750719 \mathrm{~S} & 36.534478 \mathrm{E} \\ 0.779508 \mathrm{~S} & 36.547194 \mathrm{E} \\ 0.317531 \mathrm{~S} & 36.817467 \mathrm{E} \\ 0.850442 \mathrm{~S} & 36.554523 \mathrm{E} \\ 0.77795 \mathrm{~S} & 36.526239 \mathrm{E} \\ 0.901606 \mathrm{~S} & 36.572089 \mathrm{E} \\ 0.934444 \mathrm{~S} & 36.601244 \mathrm{E}\end{array}$

$$
\begin{array}{ll}
0.704581 & 36.110097 \mathrm{E} \\
0.765033 & 36.129503 \mathrm{E} \\
0.799786 & 36.135525 \mathrm{E}
\end{array}
$$

\begin{tabular}{ll}
0.2155944444 & \\
$S$ & $36.611577778 \mathrm{E}$ \\
0.2282138889 & \\
$S$ & $36.312558333 \mathrm{E}$ \\
$0.219580556 \mathrm{~S}$ & $36.313230556 \mathrm{E}$ \\
$0.266316667 \mathrm{~S}$ & $36.316180556 \mathrm{E}$ \\
$0.29433333 \mathrm{~S}$ & $36.318011111 \mathrm{E}$ \\
& 36.3558472222 \\
$0.285588889 \mathrm{~S}$ & $\mathrm{E}$ \\
& 36.3267666667 \\
$0.294158333 \mathrm{~S}$ & $\mathrm{E}$ \\
& 36.3334166667 \\
$0.304763889 \mathrm{~S}$ & $\mathrm{E}$ \\
0.3230722222 & 36.3407972222 \\
$\mathrm{~S}$ & $\mathrm{E}$ \\
0.3332416667 & 36.3451388889 \\
$\mathrm{~S}$ & $\mathrm{E}$ \\
$0.346861111 \mathrm{~S}$ & $36.348611111 \mathrm{E}$ \\
0.3499527778 & 36.3487638889 \\
$\mathrm{~S}$ & $\mathrm{E}$ \\
$0.353719 \mathrm{~S}$ & $36.3533719 \mathrm{E}$ \\
0.3528555556 & \\
$\mathrm{~S}$ & $0.35331762 \mathrm{E}$ \\
$0.358375 \mathrm{~S}$ & $\mathrm{E}$ \\
& \\
1.2326972222 & \\
$N$ & $35.615075 \mathrm{E}$ \\
1.1116777778 & 35.7481694444 \\
$N$ & $\mathrm{E}$ \\
00.7598194444 & 35.5611722222 \\
$N$ & $\mathrm{E}$ \\
00.495972222 & 35.5475138889 \\
$N$ & $\mathrm{E}$ \\
00.4030777778 & 35.5849777779 \\
$N$ & $\mathrm{E}$ \\
00.3399972222 & \\
$N$ & $35.590122222 \mathrm{E}$ \\
& \\
\hline &
\end{tabular}




\section{Appendix C: Estimated Error in Latitude \& Longitude Measurement}

Latitude and Longitude were recorded in decimal degrees and generally rounded it off at the $6^{\text {th }}$ decimal place.

$1 / 100,000$ of a degree of longitude is about -0.072 inches $(-0.1853 \mathrm{~cm})$ at the equator (a negligible distance) given that one nautical mile equals one degree of longitude at the equator. See math that follows.

Math:

1 Nautical Mile $=6076.12 \mathrm{ft}=1$ minute of longitude at the equator, giving $60 \mathrm{NM}$ per degree

Therefore: $0.000001^{\circ}=(60 * 6076.12 \mathrm{ft}) * 0.000001=0.3645672 \mathrm{ft}$ or $4.37486064 \mathrm{in}$ at the equator that's $0.11112 \mathrm{~m}$ or $11.112 \mathrm{~cm}$

$(1852 \mathrm{~m} * 60) * 0.000001=0.11112 \mathrm{~m}$ or $11.112 \mathrm{~cm}$

However, the accuracy of positions was likely no more accurate than the $5^{\text {th }}$ decimal place or $1 / 100,000$ of a degree; changing the co-responding numbers to $3.645672 \mathrm{ft}$ equals 43.748064 in or $111.12 \mathrm{~cm}$. or $-1.11 \mathrm{~m}$. This accuracy measure applies the error in Longitude only at the equator; still 33 inches is negligible on a global scale. The error in latitude would be about the same. Since the survey area straddles the equator, the estimates at the equator should be roughly valid across the considered survey area. This accuracy is comparable to that of a modern GPS unit. It would be more than sufficient to find the location of a feature in the field with a GPS unit--and no problem to find the point within the data used or even in future datasets. 


\section{Appendix D: Fault Morphology Summary}

Primary examples of fault morphologies in the Southern Kenya Rift are presented below. The three faults classifications are roughly listed from suggested youngest to most mature forms. However, most scarps examined for this report appear to be the result of a sequence of events with separate periods of faulting and separate emplacements of lava flows-thus difficult to categorize. Further complication this picture are differences in the history of mass-wasting events between fault scarps. More advanced and detailed research is needed to categorize faults and fault segments by age, using the sigmoid endpoint theory presented in this report.

Fault Morphology 1: Youngest - Most "Pristine State" Fault Observed

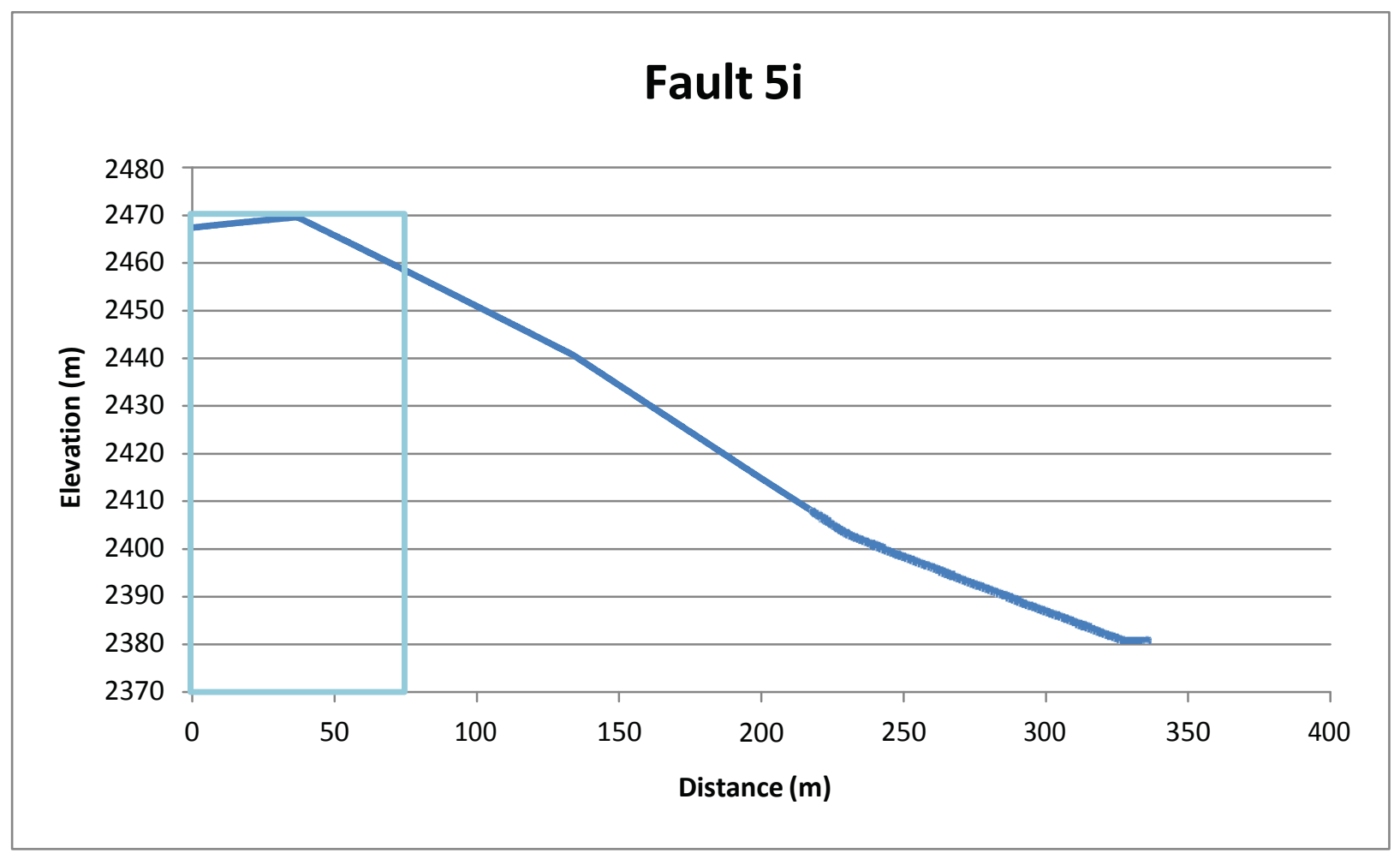

This observed fault is likely in a fairly "pristine state" and thus appears to be a relatively young and so far not significantly changed by erosional expected events. 
Fault Morphology 2 - Distinct Bumps - Fault Segments -Sequence of Volcanic Events

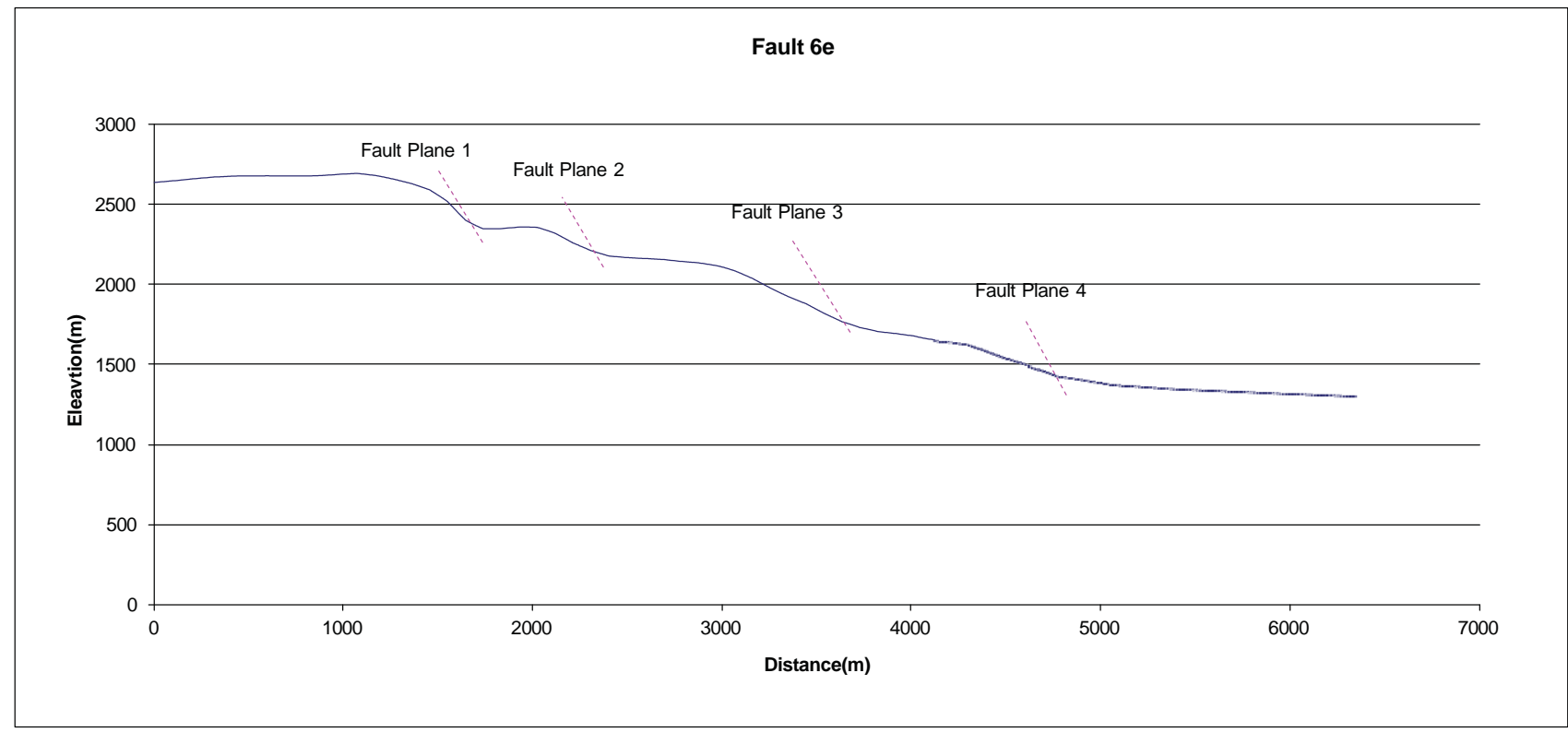

Most scarps examined as a part of this report appear to be the result of a sequence of events with separate periods of faulting and separate emplacements of lava flow since they are the major rift defining faults, and thus are difficult to categorize. In some cases, faulting appears followed by a quiescent period during which the scarp was eroded and then buried by extrusive volcanic material and then erosion again. In others, like the case above, the escarpment appears to consist of multiple separate parallel faults, aka a fault system, as opposed to a single larger fault. In the case above there appears to be four separate faults along the profile line each with its own fault plane. It should be noted that each of these fault scarps appears to be sigmoidal to the extent made possible by the fault below it. 
FaultMorphology3-Sigmoid Angle ofRepose-OldestFault

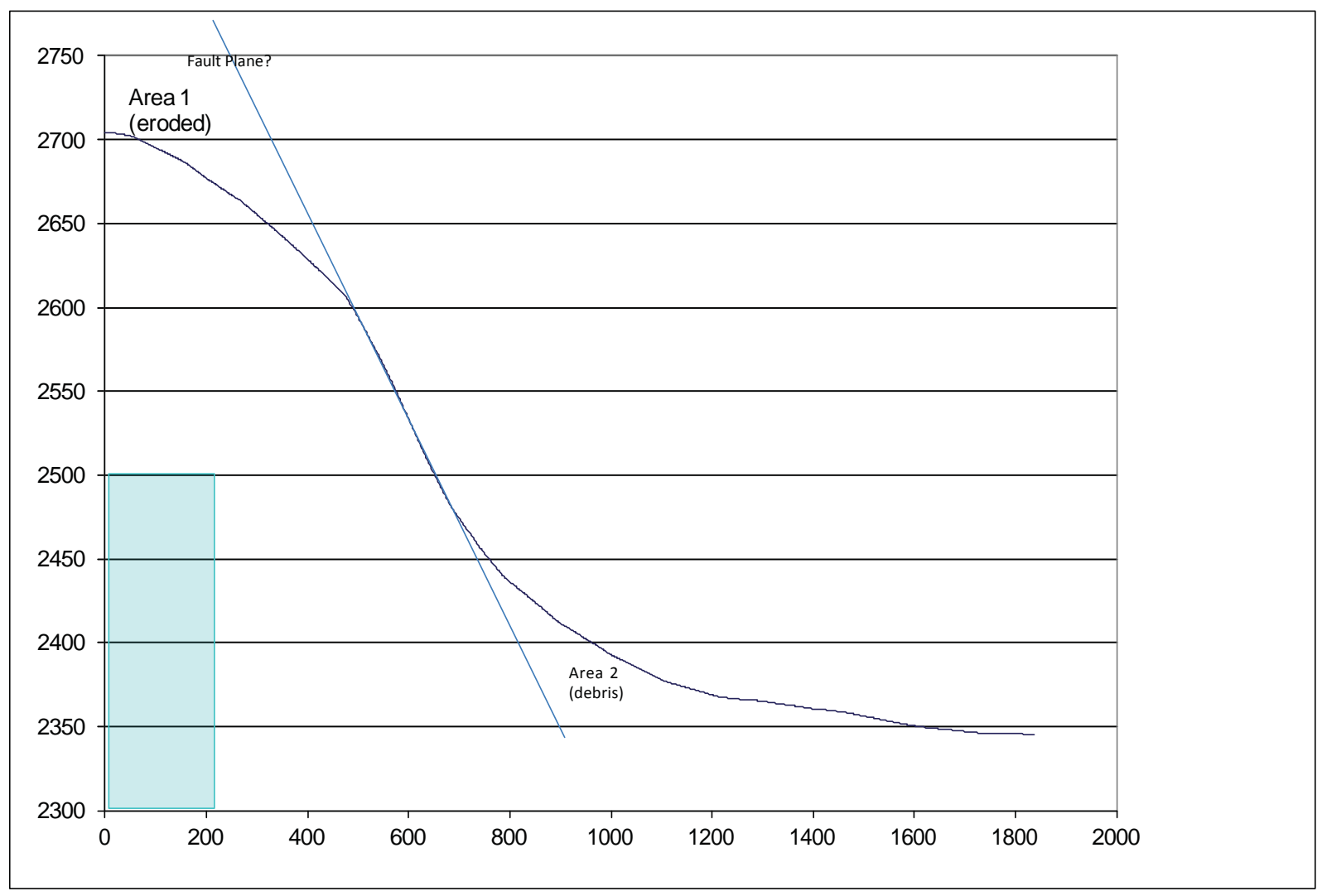

This fault appears to have eroded in a sigmoid fashion and thus appears to be older, perhaps even at the "end-state" of erosion. Once a scarp reaches this shape it should theoretically be stable since there's nothing left to erode by gravity from top to bottom. Theoretically, the fault would continue to erode over geologic time, but retain its sigmoidal shape until the whole region is eroded flat. Bearing in mind that this is a two-dimensional slice of a three-dimensional structure, the area is roughly equivalent to volume in the transition from 3D to 2D. The amount of material that is missing from the top (Area 1) roughly appears to equal the amount of material in the debris pile at the bottom of the scrap (Area 2) and thus to be at the sigmoid state. This makes sense since the material from above has to go somewhere by gravity and the most likely place is to the bottom of the slope where it runs out of energy to move, thus the eroded volume or area should equal the debris pile at the bottom. 